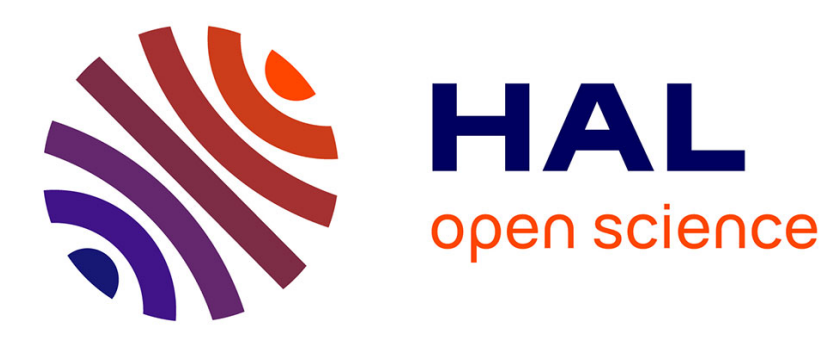

\title{
Direct Photomodification of Polymer Surfaces: Unleashing the Potential of Aryl-Azide Copolymers
}

Anita Schulz, Antonio Stocco, Audrey Bethry, Jean-Philippe Lavigne, Jean

Coudane, Benjamin Nottelet

\section{- To cite this version:}

Anita Schulz, Antonio Stocco, Audrey Bethry, Jean-Philippe Lavigne, Jean Coudane, et al.. Direct Photomodification of Polymer Surfaces: Unleashing the Potential of Aryl-Azide Copolymers. Advanced Functional Materials, 2018, 28 (30), pp.1800976. 10.1002/adfm.201800976 . hal-01909547

\section{HAL Id: hal-01909547 \\ https://hal.science/hal-01909547}

Submitted on 29 Nov 2019

HAL is a multi-disciplinary open access archive for the deposit and dissemination of scientific research documents, whether they are published or not. The documents may come from teaching and research institutions in France or abroad, or from public or private research centers.
L'archive ouverte pluridisciplinaire HAL, est destinée au dépôt et à la diffusion de documents scientifiques de niveau recherche, publiés ou non, émanant des établissements d'enseignement et de recherche français ou étrangers, des laboratoires publics ou privés. 


\title{
Direct Photomodification of Polymer Surfaces: Unleashing the Potential of Aryl-Azide Copolymers
}

Anita Schulz, Antonio Stocco, Audrey Bethry, Jean-Philippe Lavigne, Jean Coudane, Benjamin Nottelet*

Dr. Anita Schulz, Audrey Bethry, Prof. Jean Coudane, Dr. Benjamin Nottelet

IBMM, Université de Montpellier, CNRS, ENSCM, Montpellier, France.

E-mail: Benjamin.Nottelet@umontpellier.fr

Dr. Antonio Stocco

L2C, Université de Montpellier, CNRS, Montpellier, France.

Prof. Jean Philippe Lavigne

INSERM unité 1047, Université de Montpellier, Nîmes, France; Service de microbiologie, CHU Caremeau, Nîmes, France.

Keywords: photochemistry, poly(2-oxazoline)s, antibacterial, polymer surface, aryl-azide

\begin{abstract}
The possibility to impart surface properties to any polymeric substrate using a fast, reproducible and industrially friendly procedure, without the need for surface pre-treatment, is highly sought after. This is in particular true in the frame of antibacterial surfaces to hinder the threat of biofilm formation. In this study we demonstrate the potential of aryl-azide polymers for photo-functionalization and the importance of the polymer structure for an efficient grafting. The strategy is illustrated with a UV-reactive hydrophilic poly(2-oxazoline) based copolymer, which can be photografted onto any polymer substrate that contains carbonhydrogen bonds to introduce antifouling properties. Through detailed characterization it is demonstrated that the controlled spatial distribution of the UV-reactive aryl-azide moieties within the poly(2-oxazline) structure, in the form of pseudo gradient copolymers, ensures higher grafting efficacy than other copolymer structures including block copolymers. Furthermore, it is found that the photografting results in a covalently bound layer, which is thermally stable and causes a significant anti-adherence effect and biofilm reduction against $E$. coli and S. epidermidis strains while remaining non-cytotoxic against mouse fibroblasts.
\end{abstract}




\section{Introduction}

The assembly of microbial cells within a self-produced extracellular matrix of proteins, polysaccharides, nucleic acids and lipids on a surface is a quickly occurring and highly undesirable process known as biofilm formation. Biofilm causes many problems in very diverse fields of applications: in the container-shipping industry it adds weight and friction, in the oil and water desalination industry it blocks filtration and causes corrosion, in the food industry it contaminates and in hospitals it is responsible for almost half of the hospital acquired infections and sometimes even death. ${ }^{[1-3]}$ The relevance of this problem is reflected in the numerous approaches to obtain antibacterial surfaces. Such antibacterial surface properties can be achieved through bioactive or biopassive surface modifications. ${ }^{[4,5]}$ Bioactive coatings kill bacteria upon approach e.g. through positive charges or by releasing substances such as antimicrobial agents or silver ions. The activity can be hampered over time though, due to limited release of the substances or the deposition of dead bacteria on the surface. More importantly the release of antimicrobial agents can cause the emergence of resistant strains of bacteria. In contrast, biopassive strategies prevent the adhesion of bacteria on the surface, but are not bactericidal. Such a biopassive surface modification can be realized through the employment of hydrophilic graft polymers with anti-fouling properties. These polymers can be attached either through a grafting from (polymerization from the surface) or through a grafting onto (functional polymer grafted to the surface) approach. Both grafting methods have their merits and drawbacks, but in general require reactive groups either on the surface, in the graft polymer or both. Here versatile chemical motifs, such as organosilanes, which attach to various metal surfaces, are essential tools to introduce functional groups or graft polymers directly to the substrates. In recent years, mussel adhesive proteins and their peptide mimics have also gained increased interest, since they not only attach to multiple metal surfaces, but also to polymer substrates. ${ }^{[6,7]}$ However their attachment is based on intermolecular forces such as hydrogen bonding, electrostatic and hydrophobic interactions 
and $\pi-\pi$ stacking, but not covalent bonds. ${ }^{[6]}$ In order to achieve covalent conjugation to polymer substrates, the surface has to be activated, often via complex and time-consuming chemical reactions, which can even lead to degradation of the surface material. In addition, such surface activation processes and the subsequent functionalization are often tailored to the chemical composition of the surface and not conferrable to other surface materials. This was in fact, illustrated by our recent work where a "surface preactivation / grafting to" approach was successfully reported to yield potent antibacterial polyester surfaces. ${ }^{[8,9]}$ Despite efficient, non-degrading and biocompatible click ligation strategies, in particular thiol-yne photoaddition, the main disadvantage was the required preactivation step that was only applicable to aliphatic polyesters, thus limiting the potential of the approach to a family of polymer substrates.

To overcome this limitation and with aim to provide flexible and versatile surface modification on a wide range of polymer substrates, we focus in this work on UV-activated nitrene species. It is well known, that nitrenes can insert into carbon-hydrogen bonds, a common chemical entity in most polymer substrates. Here aryl-azides have proven to be very stable precursors, which photolyse efficiently into the reactive nitrene species. ${ }^{[10]}$ Already in 1969 an aryl-azide derivative was utilized as a labeling reagent for an antibody by Fleet et al. ${ }^{[10]}$ Since then aryl-azides have been used for various applications, such as radioactive labeling of phospholipids, ${ }^{[11,12]}$ crosslinking of polymer chains, ${ }^{[13]}$ and introduction of functional groups on substrates, ${ }^{[14,15]}$ and in polymer chains. ${ }^{[16,17]}$ Interestingly though, despite its versatility, the exploitation of this photoreactive moiety remained scarce over the last decades to directly graft UV-reactive polymers chains onto most polymeric surfaces. Zhu et al. reported on aryl-azide chitosan/heparin complexes to inhibit platelets adhesion and activation. ${ }^{[18]} \mathrm{Li}$ et al. described fluorinated acrylate copolymers for hydrophobization of fabrics. ${ }^{[19]}$ Hadler et al. investigated the photochemical modification of polyimide Kapton ${ }^{\circledR}$ 
substrates with various hydrophilic polymers, which were functionalized with aryl azide groups in a post analog reaction. ${ }^{[20]}$ However, in all cases the aryl-azide moieties were randomly embedded in the polymer chain and polymer block, respectively. It is our belief that this lack of exploitation is mainly due to the absence of systematic study dedicated to the repartition of aryl-azide moieties in the polymer chains and its influence on the photografting efficiency. To the best of our knowledge, this approach has never been investigated before to realize antibacterial surfaces using a pseudo gradient or block aryl-azide containing antifouling copolymer exhibiting a controlled spatial distribution of the aryl-azide moieties for an efficient surface anchoring (Figure 1A).

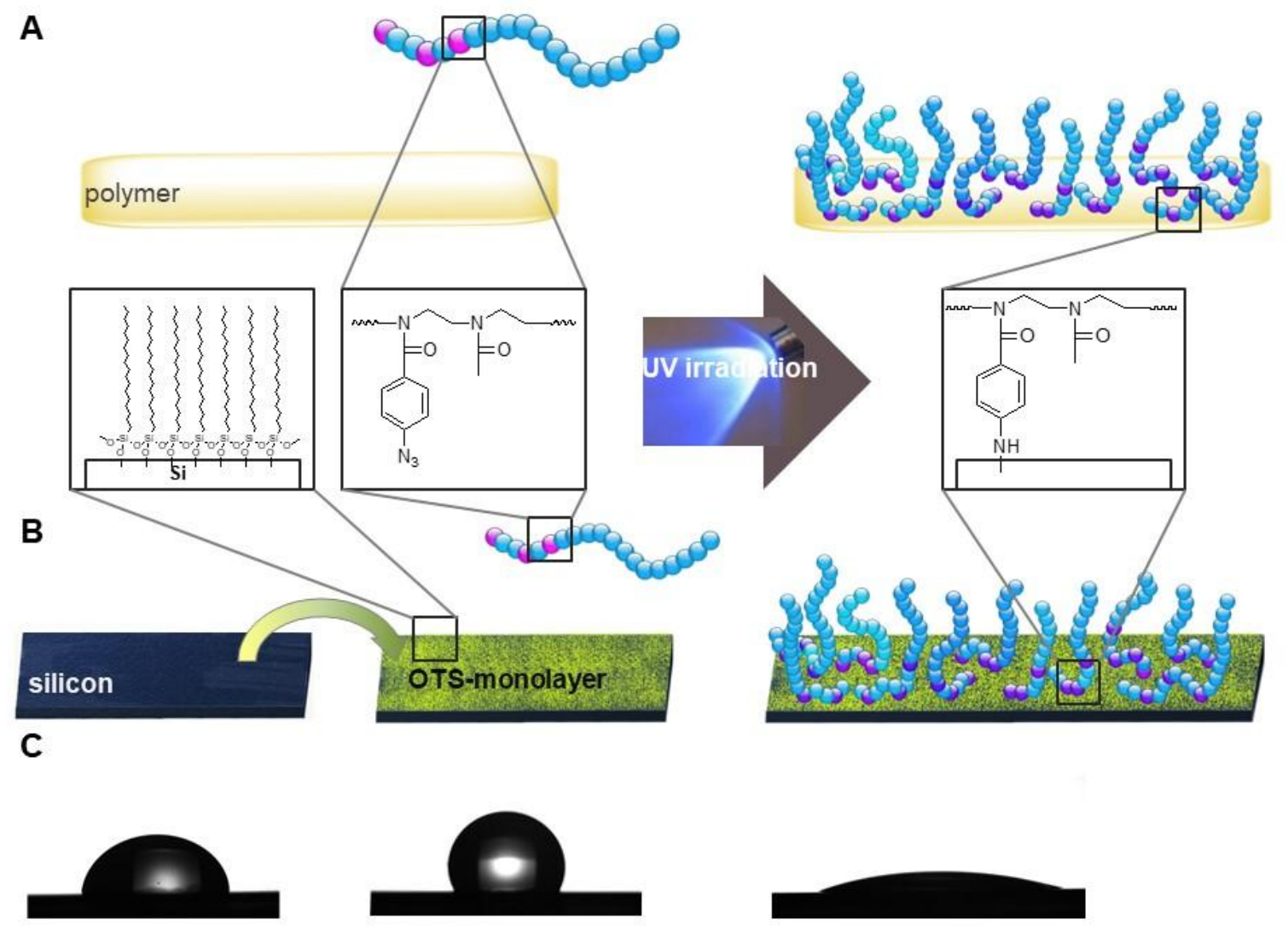

Figure 1. Schematic illustration of the grafting process of poly(2-oxazoline) copolymers onto polymer substrates (A) and OTS-monolayer deposited on silicon wafer (B) with the help of UV irradiation. Static water contact angles (C) are shown for silicon (left), OTS-monolayer (middle) and grafted poly(2-oxazoline) layer (right).

\section{Results and Discussion}




\subsection{Photoinsertion of copolymers bearing a single aryl-azide chain-end moiety}

To introduce aryl-azide groups with control over quantity and location in the polymer structure, living polymerization is the method of choice. Initially, we used an aryl-azide bearing initiator, 4-azidoaniline $(\mathrm{AzPh})$, for the living ring-opening polymerization of sarcosine- $N$-carboxyanhydride (Sar-NCA) to ensure that each polymer chain featured one aryl-azide moiety at the chain end. The resulting polymer, polysarcosine (PSar), is also more and more recognized as an interesting alternative to polyethylene glycol (PEG), the current standard for antifouling coatings. ${ }^{[21,22]}$

Methanolic solutions of the polymer ( $\mathrm{c}=10$ or $20 \mathrm{~g} / \mathrm{L}$ ) were spray-coated on polypropylene (PP) and poly(lactic acid) (PLA) substrates, which were warmed to $50-60^{\circ} \mathrm{C}$ to ensure quick evaporation of the solvent. The substrates were exposed to UV light by placing it under a chromatography lamp $(254 \mathrm{~nm}, 8 \mathrm{~W})$ at a distance of approx. $3 \mathrm{~cm}$ for $20 \mathrm{~min}$. The coating step was repeated up to five times, with in between washing steps, to remove UV-deactivated polymer chains from the surface. While the emergence of a nitrogen peak in X-ray photoelectron spectra (XPS) confirmed the attachment of AzPh-PSar on PP (Figure 2) and PLA substrates (Figure S1), water contact angle measurement did not show an increase of the surface energy (PP: $103^{\circ} \rightarrow 97^{\circ}$; PLA: $67^{\circ} \rightarrow 68^{\circ} ; 10 \mathrm{~g} / \mathrm{L}$, AzPh-PSar ${ }_{100}$ ). This absence of improvement was attributed to the inherent roughness of the substrates surfaces conferred by the hot-plate press process used to prepare the PP and PLA substrates. ${ }^{[23]}$

Thus, as a model system, a silicon wafer with an octadecyltrichlorosilane (OTS) monolayer (Figure 1B), was employed to facilitate a more suitable surface characterization. Here, the water contact angle of the surfaces dropped from $\sim 105^{\circ}$ with just the OTS monolayer to $\sim 80^{\circ}$ after multiple coating steps. This drop was caused by a grafted polymer layer of only a few nm thickness as determined by ellipsometry measurements (Table 1). 
Table 1. Overview of various parameters (polymer structure, concentration and irradiation time) and their influence on the grafting efficacy expressed in layer thickness and static water contact angle (OTS-monolayer deposited on silicon wafer used as model substrate).

\begin{tabular}{lllll}
\hline polymer & $\begin{array}{c}\text { conc. } \\
{[\mathrm{g} / \mathrm{L}]}\end{array}$ & $\begin{array}{l}\text { irradiation } \\
\text { time }[\mathrm{min}]\end{array}$ & $\begin{array}{l}\text { thickness } \\
{[\mathrm{nm}]}\end{array}$ & $\begin{array}{l}\text { static } \\
\text { contact } \\
\text { angle }^{\mathrm{a}}\left[{ }^{\circ}\right]\end{array}$ \\
\hline AzPh-PSar $_{10}$ & 20 & $5 \times 20$ & $2.1 \pm 0.2$ & $83 \pm 9$ \\
AzPh-PSar $_{100}$ & 20 & $5 \times 20$ & $0.9 \pm 0.1$ & $82 \pm 9$ \\
$\mathrm{P}(\mathrm{AzPhOx})_{5}-b-(\mathrm{MeOx})_{100}$ & 10 & $5 \times 20$ & $0.5 \pm 0.6$ & $54 \pm 6$ \\
$\mathrm{P}(\mathrm{AzPhOx})_{5}-b-(\mathrm{MeOx})_{100}$ & 20 & $5 \times 20$ & $1.7 \pm 0.5$ & $53 \pm 15$ \\
$\mathrm{P}\left[(\mathrm{AzPhOx})_{5}-c o-(\mathrm{MeOx})_{10}\right]-b-(\mathrm{MeOx})_{90}$ & 10 & $1 \times 20$ & $11.8 \pm 0.9$ & $63 \pm 8$ \\
$\mathrm{P}\left[(\mathrm{AzPhOx})_{5}-c o-(\mathrm{MeOx})_{10}\right]-b-(\mathrm{MeOx})_{90}$ & 10 & $5 \times 20$ & $13.6 \pm 2.2$ & $33 \pm 12$ \\
$\mathrm{P}\left[(\mathrm{AzPhOx})_{5}-c o-(\mathrm{MeOx})_{10}\right]-b-(\mathrm{MeOx})_{90}$ & 20 & $5 \times 20$ & $5.5 \pm 0.3$ & $40 \pm 7$ \\
\hline
\end{tabular}

${ }^{a}$ Data is represented as means $\pm \operatorname{SEM}(\mathrm{n}=3)$.

\subsection{Photoinsertion of aryl-azide block or gradient copolymers}

Since the grafting could not be improved further by increasing the AzPh-PSar concentration or irradiation time, we decided to introduce more aryl-azide groups per polymer chain. For this poly(2-oxazoline) based block and pseudo gradient copolymers were prepared. Poly(2oxazoline)s have gained great interest as biomaterial in the last years, ${ }^{[21,24]}$ in particular the hydrophilic poly(2-methyl-2-oxazoline) (PMeOx) that features properties similar to PSar and PEG. More importantly though, monomers containing the aryl-azide group are synthetically readily accessible. ${ }^{[25]}$ A small fraction of such an aryl-azide containing monomer, 2-(4azidophenyl)-2-oxazoline (AzPhOx), was copolymerized with $\mathrm{MeOx}$, enough to ensure multiple attachment points, but without significantly diminishing the copolymers hydrophilicity (Table 1). Also the spatial distribution was varied by either introducing $\mathrm{AzPhOx}$ as a block or by mixing it with $\mathrm{MeOx}$ to obtain a pseudo gradient distribution in the polymer. Despite increasing the aryl azide content, all poly(2-oxazoline)s were readily soluble in methanol $(\mathrm{c}>50 \mathrm{~g} / \mathrm{L})$, allowing the utilization of the same coating process as used for AzPh-PSar.

Poly(2-oxazoline) containing only one aryl azide unit $\left.\left(\mathrm{P}(\mathrm{AzPhOx})_{1} \text {-co-( } \mathrm{MeOx}\right)_{100}\right)$ showed similar results as AzPh-PSar. The water contact angles of OTS monolayers grafted with 
$\mathrm{P}(\mathrm{AzPhOx})_{1}-\mathrm{co}-(\mathrm{MeOx})_{100}$ dropped only to $82^{\circ}$. As predicted, increasing the aryl azide content within the poly(2-oxazoline) chains led to a more efficient grafting of OTS monolayers (Table 1), and PP and PLA substrates ((PP: $103^{\circ} \rightarrow 75^{\circ}$; PLA: $67^{\circ} \rightarrow 56^{\circ} ; 20 \mathrm{~g} / \mathrm{L}$ $\left.\mathrm{P}\left[(\mathrm{AzPhOx})_{5}-c o-(\mathrm{MeOx})_{10}\right]-b-(\mathrm{MeOx})_{90}\right)$. Interestingly though, the best performances were observed with the pseudo gradient copolymer $\mathrm{P}\left[(\mathrm{AzPhOx})_{5}-c o-(\mathrm{MeOx})_{10}\right]-b-(\mathrm{MeOx})_{90}$ and not with the block copolymer $\mathrm{P}(\mathrm{AzPhOx})_{5}-b-(\mathrm{MeOx})_{100}$. It seems that more flexibility between the aryl-azide moieties facilitates multiple attachments to the surface rather than enhanced orientation of the chains towards the surface due to pronounced amphiphilicity. Already a single coating step with $\mathrm{P}\left[(\mathrm{AzPhOx})_{5}-c o-(\mathrm{MeOx})_{10}\right]-b-(\mathrm{MeOx})_{90}$ at half the polymer concentration surpassed the best coating results of polymers with a single aryl azide group. With further coating steps water contact angles as low as $33 \pm 12^{\circ}$ could be achieved. In contrast, the thickness of the grafted polymer layer increased only marginally with additional coating steps (Table 1). This indicates that rather than grafting layer on top of the previous layer the repetition increases the grafting density. Grafted polymer layer thicknesses of around $10 \mathrm{~nm}$ were also corroborated by atomic-force microscopy (AFM, Figure 2C). Moreover, XPS analysis confirmed the presence of poly(2-oxazoline) on the surfaces of PP (Figure 2) and PLA substrates (Figure S1). 


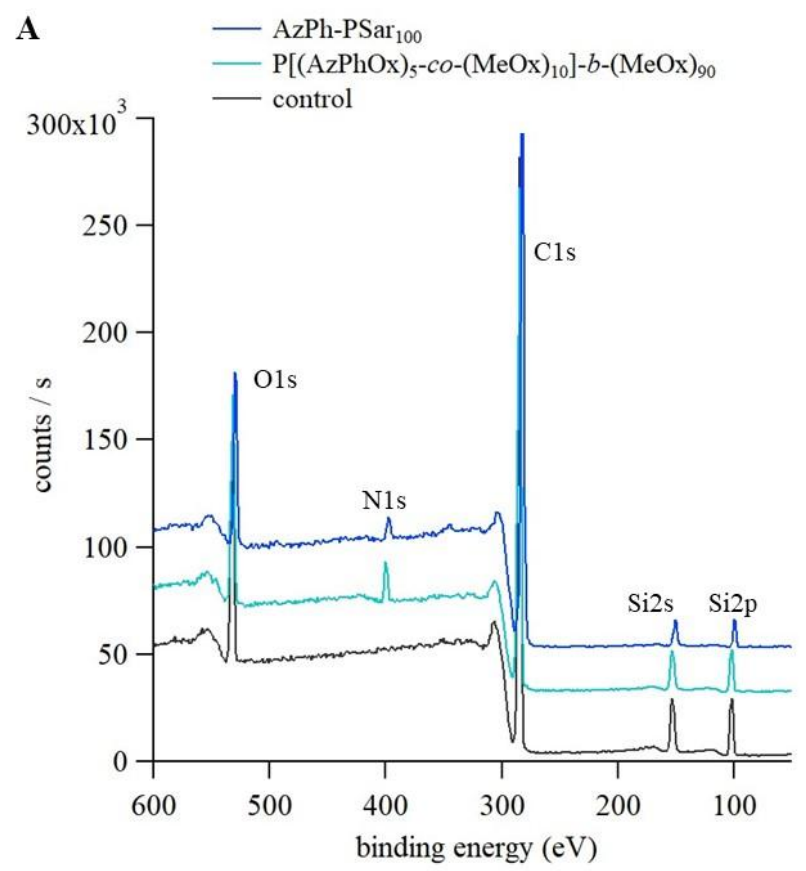

\begin{tabular}{lccc}
$\mathbf{B}$ & & & \\
\hline $\mathbf{P P}$ & $\mathrm{C} 1 \mathrm{~s}$ & $\mathrm{O} 1 \mathrm{~s}$ & $\mathrm{~N} 1 \mathrm{~s}$ \\
\hline control & 86.4 & 13.6 & \\
$\mathrm{PSar}_{100}$ & 88.8 & 9.2 & 2.0 \\
$\mathrm{P}\left[(\mathrm{AzPhOx})_{5}-\mathrm{co}-(\mathrm{MeOx})_{10}\right]-b-(\mathrm{MeOx})_{90}$ & 82.0 & 13.9 & 4.1 \\
\hline
\end{tabular}

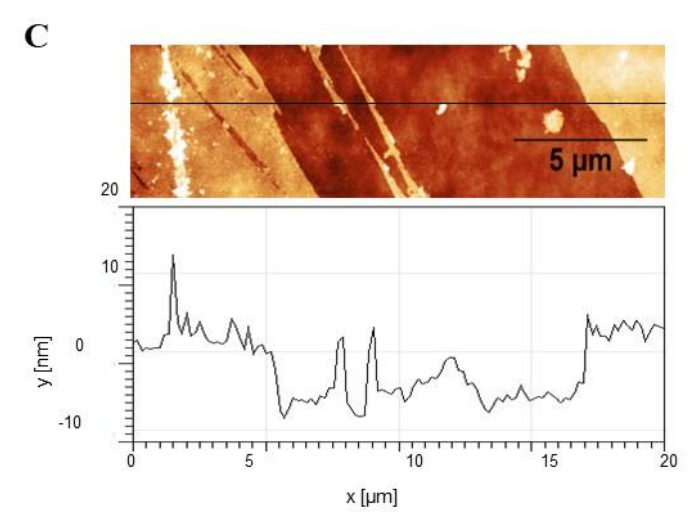

Figure 2. XPS full spectrum of PP substrates (A) and the atomic percentage (B). AFM height scan and corresponding height profile of $\mathrm{P}\left[(\mathrm{AzPhOx})_{5}-c o-(\mathrm{MeOx})_{10}\right]-b-(\mathrm{MeOx})_{90}$ grafted onto an OTS monolayer $(\mathrm{C})$.

\subsection{Versatility and stability of the surface modification}

To visualize the coating process, $\mathrm{P}\left[(\mathrm{AzPhOx})_{5}-c o-(\mathrm{MeOx})_{10}\right]-b-(\mathrm{MeOx})_{90}$ was labeled with the fluorescence dye Rhodamine B (Figure S2), and grafted onto various polymer substrates to investigate its versatility (Figure 3). In addition, the coated surfaces were submerged in $100^{\circ} \mathrm{C}$ hot water for $15 \mathrm{~h}$ to test the thermal stability of the surface functionalization. While PP, PLA, polyethylene terephthalate (PET, vascular graft) and polyurethane (PU, percutaneous nephrostomy catheter) were homogeneously coated with the grafted polymer chains and did not suffer any significant loss of the functionalization after the thermal treatment, we observed a scarce and blotchy distribution on silicone, which was almost completely removed after $15 \mathrm{~h}$ in boiling water (Figure S3). The lack of a comprehensive surface functionalization was attributed to the poor wettability of the silicone substrate with the methanolic $\mathrm{P}\left[(\mathrm{AzPhOx})_{5}-c o-(\mathrm{MeOx})_{10}\right]-b-(\mathrm{MeOx})_{90}$ solution. It remains unclear though if that also caused the failed covalent attachment or if the materials itself is unsuitable for the procedure. 

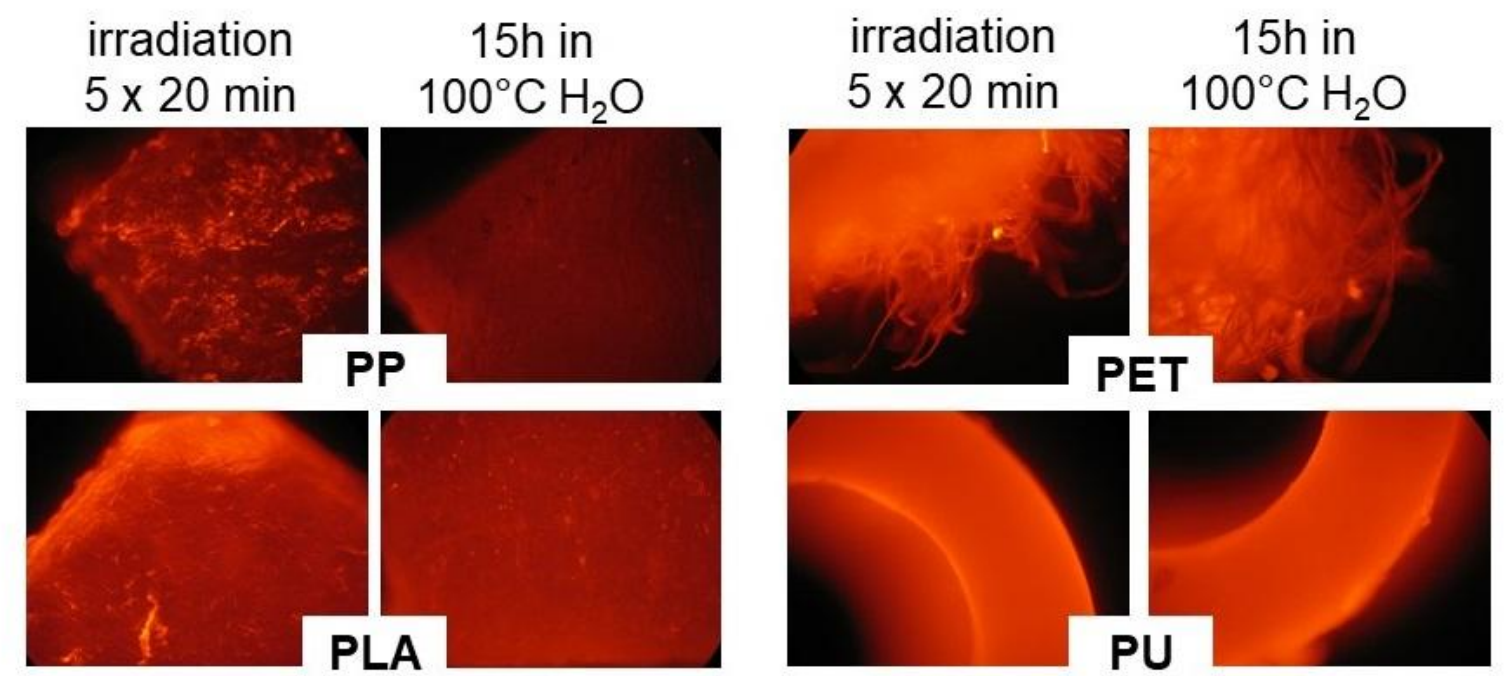

Figure 3. Visualization of the grafting process after five coating steps and its thermal stability in $100^{\circ} \mathrm{C}$ hot water by utilizing a fluorescent labeled $\mathrm{P}\left[(\mathrm{AzPhOx})_{5}-c o-(\mathrm{MeOx})_{10}\right]-b-(\mathrm{MeOx})_{90}$ copolymer on various materials.

To corroborate the indication of covalent attachment due to the presence of aryl-azide groups and to rule out generation of radicals on the substrates surface itself during UV-irradiation, which could lead to covalent bonds between the polymer chains and the surface, we repeated the experiments with a Rhodamine B labeled $\mathrm{PMeOx}$ homopolymer and $\mathrm{P}\left[(\mathrm{AzPhOx})_{5}-\mathrm{co}-\right.$ $\left.(\mathrm{MeOx})_{10}\right]-b-(\mathrm{MeOx})_{90}$ with deactivated aryl azide groups $(60$ min $\mathrm{UV}$ irradiation of the polymer solution prior grafting). While PMeOx does not bind to the surface, the inactivated $\mathrm{P}\left[(\mathrm{AzPhOx})_{5}-c o-(\mathrm{MeOx})_{10}\right]-b-(\mathrm{MeOx})_{90}$ adheres marginally to PP and quite strongly to PLA (Figure S4-5). Thus the UV-active pseudo gradient copolymer is most likely not solely attached to the surfaces through covalent bonds alone but also through intermolecular forces.

\subsection{Cytocompatibility and antibacterial activity of the modified surfaces}

The cytocompatibility and antibacterial activity of the coated PP and PLA surfaces were tested. Cytocompatibility was tested via a cell proliferation assay (direct contact) with murine fibroblast cell line L929 (ISO 10993-5). The cells were allowed to adhere to the coated PP and PLA substrates for $3 \mathrm{~h}$. Subsequently the growth of the adhered cells was followed over 9d (Figure 4A). While none of the substrates performed as well as the tissue culture-treated 
polystyrene (TCPS), the difference in cell proliferation on non-coated and coated substrates was either slightly improved (PP) by the coating or very similar (PLA). However, when the adherence of bacteria was tested significant changes were observed between the untreated and coated surfaces (Figure 4B). For both polymer substrates PP and PLA, the coating caused a drop of 2 to 3 orders of magnitude in the adherence of the reference bacteria strains $S$. epidermidis ATCC49461 and E. coli CFT073. This anti-adherence property of the coating lead to a strong reduction of biofilm formation (Figure 4C). In particular, biofilm formation on the grafted PLA substrates was almost completely impeded. This may be due to a higher coating density due to the additional adhesive interactions with the surface. These results are also in part seen in the anti-adherence data, but not as pronounced.
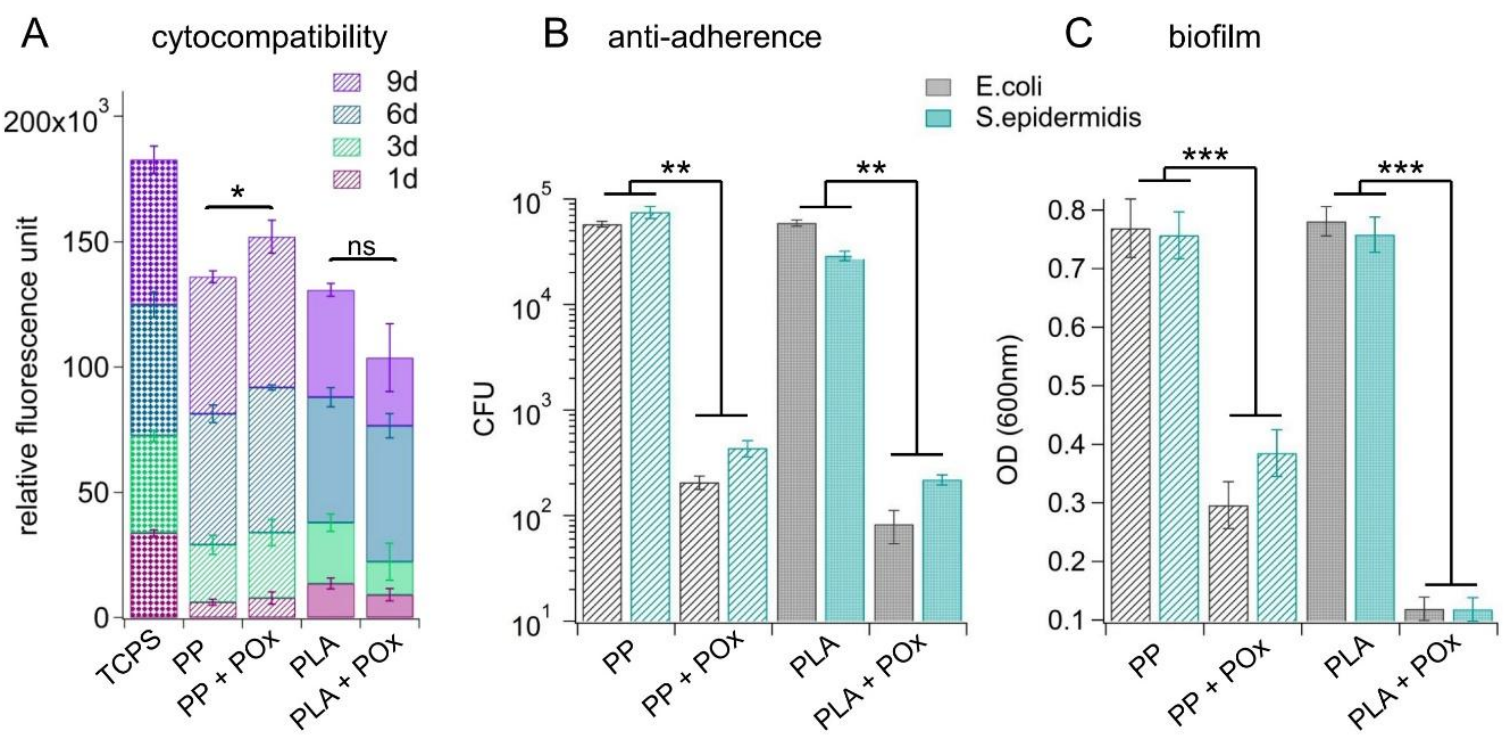

Figure 4. Effect of $\mathrm{P}\left[(\mathrm{AzPhOx})_{5}-c o-(\mathrm{MeOx})_{10}\right]-b-(\mathrm{MeOx})_{90}$ grafting onto PP and PLA substrates on cell proliferation of L929 mouse fibroblasts over 9d ( $\mathrm{n}=5)(\mathrm{A})$, adherence after 24h (B) and biofilm formation after $72 \mathrm{~h}$ (C) of S. epidermidis ATCC49461 and E. coli CFT073 bacteria. Data is represented as means \pm SD. Asterisks indicate statistical significance (t-test, ns p $>0.5, * \mathrm{p}<0.05, * * \mathrm{p}<0.01, * * * \mathrm{p}<0.001)$.

\section{Conclusion}


In conclusion, photoinsertion of rationally designed aryl-azide copolymers can be advantageously used for an efficient and direct modification of polymer surfaces. For the first time, thanks to a thorough evaluation of the macromolecular parameters, the importance of the spatial repartition of the photoreactive aryl-azide groups in the copolymer structure has been highlighted. The pseudo gradient copolymer enabled an efficient covalent grafting to introduce properties, herein antifouling properties, on chemically diverse polymer substrates. This strategy has a huge potential and could be implemented very easily in already existing value chains making this technology highly desirable for various industrial applications.

\section{Experimental Section}

Material and methods: All chemicals and materials were purchased from Sigma-Aldrich (St. Quentin Fallavier, France). 2-methyl-2-oxazoline and methyl triflate were distilled over $\mathrm{CaH}_{2}$ before usage. Silicon wafers (type P/B, SSP, 0-100 ohm.cm, $335 \mu \mathrm{m}$ thick) were ordered from UniversityWafer (Boston, USA). PET samples were cut off from a vascular graft (InterVascular Inc., 16W008, sample length 1-2 cm). PU samples were obtained from a percutaneous nephrostomy catheter (Rüsch, 340014, sample length 1-2 cm). Silicone samples were cut from suprapubic set (Rüsch, 170727, sample length 1-2 cm). Medical grade PP used for surgical mesh for hernia repair was obtained from Luxilon (Antwerp, Belgium). PLA was synthesized by bulk-ring opening copolymerization of L-lactide (92\%) and DL-lactide (8\%) (PURAC, Lyon, France) using tin 2-ethylhexanoate as catalyst. PLA and PP were pressed into 0.5-2 mm thick disks at $180^{\circ} \mathrm{C}$ and $5 \mathrm{t}$ for $30-45 \mathrm{~min}$ using a Carver Manual Bench Top Laboratory Press and subsequently cut into squares $\left(1 \mathrm{~cm}^{2}\right)$. NMR spectra were obtained 
using an AMX300 Bruker spectrometer at room temperature (RT). The spectra were calibrated using the residual protonated solvent signals. Gel permeation chromatography (GPC) was performed on a GPC system consisting of a Waters 515 HPLC pump, Viscotek VE 7510 GPC degasser, 2x PLgel 5 $\mu$ m Mixed-D (300mm) columns and a UV-detector with dimethylformamid $+0.1 \% \mathrm{LiBr}$ as eluent at a flow rate of $0.8 \mathrm{~mL} / \mathrm{min}$ and PMMA as standards. Contact angles were captured with a CCD camera (Dataphysics OCAH200) and analyzed using ImageJ software. Optical fluorescence images were taken via an Axioskop Zeiss microscope (light intensity was kept constant). For cell culture experiment, murine fibroblast cell line L929, which are recommended by the International Standard Organization (ISO) committee as an in vitro biocompatibility test model (ISO 10993-5: Biological evaluation of medical devices, part 5: tests for in vitro cytotoxicity), were purchased from Sigma-Aldrich and grown at $37^{\circ} \mathrm{C}$ in $5 \% \mathrm{CO}_{2}$ incubator, in DMEM high glucose (SigmaAldrich) supplemented with 5\% fetal bovine serum (Gibco), 2mM L-glutamine (Gibco) and 100 units per $\mathrm{ml}$ of penicillin-streptomycin (Sigma-Aldrich). Microplate reader CLARIOstar ${ }^{\circledR}$ (BMG Labtech) was used to assess cell viability via fluorescence intensity measurement thanks to Prestoblue ${ }^{\circledR}$ cell viability reagent (Invitrogen, A13261).

Monomer synthesis: The synthesis of sarcosine- $N$-carboxyanhydride was adapted from Fetsch et $a l .{ }^{[26]} \mathrm{A}$ yield of $1.63 \mathrm{~g}(62 \%)$ sarcosine- $N$-carboxyanhydride as white powder was obtained. ${ }^{1} \mathrm{H}$ NMR $\left(300 \mathrm{MHz}, \mathrm{DMSO}-d_{6}, \delta\right): 4.22\left(\mathrm{~s}, 2 \mathrm{H}, \mathrm{CH}_{2}\right), 2.86\left(\mathrm{t}, 3 \mathrm{H}, \mathrm{CH}_{3}\right)$ (Figure S6). 2-(4-azidophenyl)-oxazoline was synthesized as described by Binder and Gruber. ${ }^{[25]} \mathrm{A}$ yield of $2.49 \mathrm{~g}(44 \%)$ 2-(4-azidophenyl)-oxazoline as a yellow-brown powder was obtained. ${ }^{1} \mathrm{H}$ NMR (300 MHz, DMSO- $\left.d_{6}, \delta\right): 7.88(\mathrm{~d}, 2 \mathrm{H}, J=8.7 \mathrm{~Hz}, \mathrm{Ar} \mathrm{H}), 7.20(\mathrm{~d}, 2 \mathrm{H}, J=8.7 \mathrm{~Hz}, \mathrm{Ar}$ H), $4.39\left(\mathrm{t}, 2 \mathrm{H}, J=9.3 \mathrm{~Hz}, \mathrm{CH}_{2}\right), 3.94\left(\mathrm{t}, 2 \mathrm{H}, J=9.3 \mathrm{~Hz}, \mathrm{CH}_{2}\right)$ (Figure S7). 
Polymerization of polysarcosine: First an initiator stock solution with 4-azido-aniline hydrochloride $(\mathrm{AzPh}, \mathrm{c}=0.09 \mathrm{M})$ and triethyl amine $(\mathrm{TEA}, \mathrm{c}=0.24 \mathrm{M})$ in dry benzonitrile was prepared. Appropriate amounts of the initiator stock solutions were added to sarcosine-NCA dissolved in dry benzonitrile (c $10 \mathrm{mg} / \mathrm{mL}$ ). The reaction mixture was stirred at RT between $12 \mathrm{~h}$ and $7 \mathrm{~d}$ depending on the degree of polymerization. The polymer was precipitated twice in cold diethyl ether (10-20 fold of volume of polymer solution). After removal of the solvent and drying, the polymer was redissolved in $\mathrm{H}_{2} \mathrm{O}$ and lyophilized.

$A z P h-P S a r_{10}: 4.5 \mathrm{~mL}$ of the initiator solution $\left(\mathrm{n}_{\mathrm{AzPh}}=0.405 \mathrm{mmol}, \mathrm{n}_{\mathrm{TEA}}=1.08 \mathrm{mmol}\right)$ were added to $0.47 \mathrm{~g}$ sarcosine-NCA $(\mathrm{n}=4.08 \mathrm{mmol})$ and $1 \mathrm{~mL}$ dry benzonitrile. $223 \mathrm{mg}(77 \%)$ of a dark brown powder was obtained.

GPC (DMF) 5.4 kg/mol, Đ= 1.3 (Figure S10); ATR-FTIR: $v=2940\left(\mathrm{~m} ; v_{\mathrm{as}}\left(\mathrm{CH}_{3}\right)\right), 2120(\mathrm{~m}$, $\left.v_{\mathrm{as}}\left(\mathrm{N}_{3}\right)\right), 1640\left(\mathrm{~s}, v(\mathrm{CO})\right.$ amide I), $1490\left(\mathrm{~s}, \delta_{\mathrm{as}}\left(\mathrm{CH}_{3}\right)\right), 1401\left(\mathrm{~s}, \delta_{\mathrm{s}}\left(\mathrm{CH}_{3}\right)\right), 1227(\mathrm{~s}, v(\mathrm{C}-\mathrm{N}))$, $1100(\mathrm{~s}, v(\mathrm{C}-\mathrm{N})), 842 \mathrm{~cm}^{-1}$ (s, v (C-C)); ${ }^{1} \mathrm{H}$ NMR (300 MHz, $\left.\mathrm{D}_{2} \mathrm{O}, \delta\right): 7.51$ (bs, 2H, Ar H), 7.18 (bs, $2 \mathrm{H}, \mathrm{Ar} \mathrm{H}), 4.53-4.23\left(\mathrm{~m}, 115 \mathrm{H}, \mathrm{CH}_{2}\right), 3.12-2.94\left(\mathrm{~m}, 172 \mathrm{H}, \mathrm{CH}_{3}\right)$ (Figure S8); polymer structure by NMR: $\mathrm{PSar}_{58}, \mathrm{M}_{\mathrm{NMR}}=4.1 \mathrm{~kg} / \mathrm{mol}$.

$A z P h-P S a r_{100}: 0.22 \mathrm{~mL}$ of the initiator solution $\left(\mathrm{n}_{\mathrm{AzPh}}=0.02 \mathrm{mmol}, \mathrm{n}_{\mathrm{TEA}}=0.053 \mathrm{mmol}\right)$ were added to $0.23 \mathrm{~g}$ sarcosine-NCA $(\mathrm{n}=2.01 \mathrm{mmol})$ and $2.3 \mathrm{~mL}$ dry benzonitrile. $131 \mathrm{mg}(92 \%)$ of a yellow powder was obtained.

GPC (DMF) 7700 g/mol, Đ= 1.2 (Figure S10); ATR-FTIR: $v=2940\left(\mathrm{~m} ; v_{\mathrm{as}}\left(\mathrm{CH}_{3}\right)\right), 2120(\mathrm{w}$, $\left.v_{\mathrm{as}}\left(\mathrm{N}_{3}\right)\right), 1640\left(\mathrm{~s}, v(\mathrm{CO})\right.$ amide I), $1490\left(\mathrm{~s}, \delta_{\mathrm{as}}\left(\mathrm{CH}_{3}\right)\right), 1401\left(\mathrm{~s}, \delta_{\mathrm{s}}\left(\mathrm{CH}_{3}\right)\right), 1227(\mathrm{~s}, v(\mathrm{C}-\mathrm{N}))$, $1100(\mathrm{~s}, v(\mathrm{C}-\mathrm{N})), 842 \mathrm{~cm}^{-1}$ (s, v (C-C)); ${ }^{1} \mathrm{H}$ NMR $\left(300 \mathrm{MHz}, \mathrm{D}_{2} \mathrm{O}, \delta\right): 7.51$ (bs, 2H, Ar H), 7.19 (bs, 2H, Ar H), 4.53-4.18 (m, 256H, $\left.\mathrm{CH}_{2}\right), 3.13-2.94\left(\mathrm{~m}, 385 \mathrm{H}, \mathrm{CH}_{3}\right)$ (Figure S9); polymer structure by NMR: AzPh-PSar ${ }_{128}, \mathrm{M}_{\mathrm{NMR}}=9.1 \mathrm{~kg} / \mathrm{mol}$. 
Polymerization of poly(2-oxazoline) pseudo-gradient copolymers: An adequate amount of 2(4-azidophenyl)-oxazoline was added to an evacuated flask and dried further under high vacuum. The initiator methyl triflate (MeOTf, 1eq), and dry benzonitrile were also added under inert conditions. In case of the pseudo gradient copolymer, the first block of 2-(4azidophenyl)-oxazoline was copolymerized with part of the 2-methyl-2-oxazoline (MeOx). The reaction mixture was then stirred for $3 \mathrm{~d}$ at $80^{\circ} \mathrm{C}$. Next (the remaining) $\mathrm{MeOx}$ was added under argon flow to the reaction mixture. The polymerization was carried out for another day at $80^{\circ} \mathrm{C}$. The reaction was terminated with 3 eq 1-BOC-piperazine, which was stirred for $5 \mathrm{~h}$ at $40^{\circ} \mathrm{C}$. Subsequently an excess of potassium carbonate was added and the mixture stirred over night at RT. After centrifugation and filtration, the solvent was removed and the residue dissolved in a mixture of chloroform and methanol $(1 / 2, \mathrm{v} / \mathrm{v})$ followed by precipitation in cold diethyl ether (10-20 fold of volume of polymer solution). After a second precipitation the polymer was dried, dissolved in $\mathrm{H}_{2} \mathrm{O}$ and lyophilized. Yellow powders were obtained.

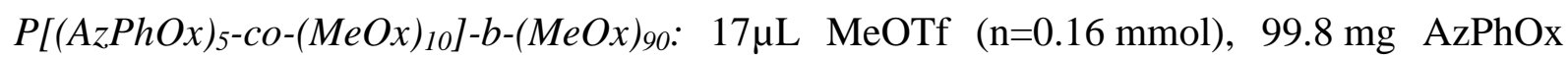
$(\mathrm{n}=0.53 \mathrm{mmol}), 0.09 \mathrm{~mL} \mathrm{MeOx}(\mathrm{n}=1.06 \mathrm{mmol}), 0.80 \mathrm{~mL} \mathrm{MeOx}(\mathrm{n}=9.4 \mathrm{mmol}), 58.1 \mathrm{mg} 1-$ BOC-piperazine $(\mathrm{n}=0.31 \mathrm{mmol})$ and $5 \mathrm{~mL}$ benzonitrile. $1.05 \mathrm{~g}(99 \%)$ of a yellow powder was obtained.

GPC (DMF) $7.8 \mathrm{~kg} / \mathrm{mol}, \mathrm{D}=1.3$ (Figure S13); ATR-FTIR: $v=2942\left(\mathrm{~m} ; v_{\mathrm{as}}\left(\mathrm{CH}_{3}\right)\right), 2126((\mathrm{w}$, $\left.v_{\text {as }}\left(\mathrm{N}_{3}\right)\right), 1633\left(\mathrm{~s}, v(\mathrm{CO})\right.$ amide I), $1421\left(\mathrm{~s}, \delta\left(\mathrm{CH}_{2}-\mathrm{CO}\right)\right), 1258(\mathrm{~m}), 1031 \mathrm{~cm}^{-1}(\mathrm{~m}) ;{ }^{1} \mathrm{H} \mathrm{NMR}$

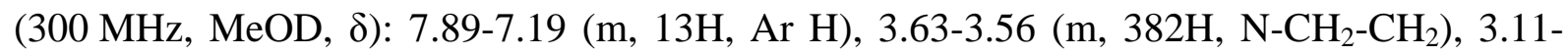
$3.07\left(\mathrm{~m}, 3 \mathrm{H}, \mathrm{CH}_{3}{ }^{\text {Ini }}\right), 2.77\left(\mathrm{bs}, 5 \mathrm{H}, \mathrm{H}^{\text {Pip }}\right), \quad 2.40-1.92\left(\mathrm{~m}, 288 \mathrm{H}, \mathrm{CO}-\mathrm{CH}_{3}\right), 1.49$ (bs, 8H, $\mathrm{CH}_{3}{ }^{\mathrm{BOC}}$ ) (Figure S12); polymer structure by NMR: $P\left[(\mathrm{Az} P h O x)_{3}-\mathrm{Co}-(\mathrm{MeOx})_{n}\right]-b-(\mathrm{MeO} x)_{m}$, $n+m=96 ; \mathrm{M}_{\mathrm{NMR}}=8.9 \mathrm{~kg} / \mathrm{mol}$. 
$P(A z P h O x)_{5}-b-(M e O x)_{100}: 17 \mu \mathrm{L}$ MeOTf ( $\left.=0.16 \mathrm{mmol}\right), 98.9 \mathrm{mg}$ AzPhOx ( $\left.\mathrm{n}=0.53 \mathrm{mmol}\right)$, $0.89 \mathrm{~mL}$ MeOx ( $\mathrm{n}=10.5 \mathrm{mmol}), 61.5 \mathrm{mg}$ 1-BOC-piperazine $(\mathrm{n}=0.33 \mathrm{mmol})$ and $5 \mathrm{~mL}$ benzonitrile. $0.94 \mathrm{~g}(94 \%)$ of a yellow powder was obtained.

GPC (DMF) $8.3 \mathrm{~kg} / \mathrm{mol}, \mathrm{Đ}=1.3$ (Figure S13); ATR-FTIR: $v=2937\left(\mathrm{~m} ; v_{\mathrm{as}}\left(\mathrm{CH}_{3}\right)\right), 2126((\mathrm{w}$, $\left.v_{\text {as }}\left(\mathrm{N}_{3}\right)\right), 1626\left(\mathrm{~s}, v(\mathrm{CO})\right.$ amide I), $1416\left(\mathrm{~s}, \delta\left(\mathrm{CH}_{2}-\mathrm{CO}\right)\right), 1241(\mathrm{~m}), 1031 \mathrm{~cm}^{-1}(\mathrm{~m}) ;{ }^{1} \mathrm{H} \mathrm{NMR}$

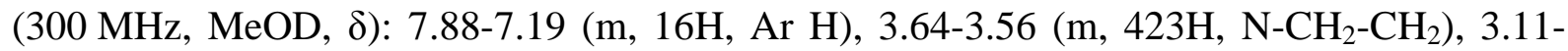
$3.07\left(\mathrm{~m}, 3 \mathrm{H}, \mathrm{CH}_{3}{ }^{\mathrm{Ini}}\right), 2.79$ (bs, 4H, $\left.\mathrm{H}^{\mathrm{Pip}}\right), 2.25-1.93\left(\mathrm{~m}, 318 \mathrm{H}, \mathrm{CO}-\mathrm{CH}_{3}\right), 1.49$ (bs, 8H, $\mathrm{CH}_{3}{ }^{\mathrm{BOC}}$ ) (Figure S11); polymer structure by NMR: $P(A z P h O x)_{4}-b-(M e O x)_{106} ; \mathrm{M}_{\mathrm{NMR}}=10.0$ $\mathrm{kg} / \mathrm{mol}$.

Polymerization of aryl-azide chain-end monofunctional poly(2-oxazoline): $119.2 \mathrm{mg} \mathrm{AzPhOx}$ was added to an evacuated flask and dried further under high vacuum. $14 \mu \mathrm{L}$ MeOTf $(\mathrm{n}=0.13 \mathrm{mmol}), 0.54 \mathrm{~mL} \mathrm{MeOx}(\mathrm{n}=6.35 \mathrm{mmol})$ and $4 \mathrm{~mL}$ anhydrous acetonitrile were also added under inert conditions. The reaction mixture was then stirred for $1 \mathrm{~d}$ at $80^{\circ} \mathrm{C}$ and terminated with $70.9 \mathrm{mg}$ 1-BOC-piperazine $(\mathrm{n}=0.38 \mathrm{mmol})$, which was stirred for another $7 \mathrm{~h}$ at $40^{\circ} \mathrm{C}$. Subsequently an excess of potassium carbonate was added and the mixture stirred over night at RT. After centrifugation and filtration, the solvent was removed and the residue dissolved in a mixture of chloroform and methanol $(1 / 2, \mathrm{v} / \mathrm{v})$ followed by precipitation in cold diethyl ether (10-20 fold of volume of polymer solution). The polymer was dried, dissolved in $\mathrm{H}_{2} \mathrm{O}$ and lyophilized. $0.33 \mathrm{~g}(50 \%)$ of a light yellow powder was obtained.

$P(A z P h O x)_{1}-c o-(M e O x)_{100}:$ GPC (DMF) $5.9 \mathrm{~kg} / \mathrm{mol}, Ð=1.3 ;{ }^{1} \mathrm{H}$ NMR $(300 \mathrm{MHz}, \mathrm{MeOD}, \delta)$ : 7.84-7.17 (m, 5H, Ar H), 3.60-3.36 (m, 385H, N-CH2- $\left.\mathrm{CH}_{2}\right), 3.07$ (m, 3H, $\mathrm{CH}_{3}{ }^{\text {Ini }}$ ), 2.34-1.89 (m, 287H, CO-CH 3 ), 1.46 (bs, $7 \mathrm{H}, \mathrm{CH}_{3}{ }^{\mathrm{BOC}}$ ) (Figure S14); polymer structure by NMR: $P(A z P h O x)_{1}-b-(M e O x)_{96} ; \mathrm{M}_{\mathrm{NMR}}=8.6 \mathrm{~kg} / \mathrm{mol}$. 
Fluorescent labeling of poly(2-oxazoline): First the end group 1-Boc-piperazine of $\mathrm{P}\left[(\mathrm{AzPhOx})_{5}-c o-(\mathrm{MeOx})_{10}\right]-b-(\mathrm{MeOx})_{90}$ was deprotected in a TFA/MeOH $(1 / 1, \mathrm{v} / \mathrm{v})$ solution (c $\sim 75 \mathrm{mg} / \mathrm{mL}$ ) for $30 \mathrm{~min}$ at room temperature. After removal of the solvent under high vacuum, the residue was dissolved in $\mathrm{H}_{2} \mathrm{O}_{\mathrm{dd}}$, dialysed $(\mathrm{MWCO}=3.5 \mathrm{kDa}$ ) for $2 \mathrm{~h}$ and lyophilized. The deprotected polymer was then dissolved in anhydrous DMF $(c=0.1 \mathrm{mg} / \mu \mathrm{L})$ and coupled with a 1.2 fold excess of Rhodamine B isothiocyanate (RBITC) and 1 eq diisopropylethylamine as base. The reaction mixture was shaken for $3 \mathrm{~d}$ in the dark at $37^{\circ} \mathrm{C}$. Excess dye was removed via dialysis. For this the reaction mixture was diluted with a 15 fold excess of $\mathrm{H}_{2} \mathrm{O}_{\mathrm{dd}}$ and transferred into a dialysis bag ( $\left.\mathrm{MWCO}=1 \mathrm{kDa}\right)$. After $4 \mathrm{~d}$ the dialysis was stopped and the polymer lyophilized. Degree of labeling was obtained spectrophotometrically and was found for the UV-active copolymer at $20.1 \%$, and for the PMeOx homopolymer at $24 \%$.

OTS monolayer: Silicon wafers were degreased with $\mathrm{CHCl}_{3}$ in ultrasonic bath for $30 \mathrm{~min}$ and subsequently immerged in $100^{\circ} \mathrm{C}$ hot piranha solution $\left(4 / 1 \mathrm{H}_{2} \mathrm{SO}_{4} / \mathrm{H}_{2} \mathrm{O}_{2}\right.$, v/v) which was gently stirred. After $2 \mathrm{~h}$ the silicon wafers were washed with $\mathrm{H}_{2} \mathrm{O}_{\mathrm{dd}}$, rinsed with ethanol and dried with Ar-flow. The pieces were separately incubated with an OTS solution $(2.5 \mathrm{mM}$ in 4/1 hexadecane/ $\mathrm{CHCl}_{3}, \mathrm{v} / \mathrm{v}$ ) at $17^{\circ} \mathrm{C}$ over night. After removal of the OTS solution, the samples were washed with $\mathrm{CHCl}_{3}$ in ultrasonic bath for $20 \mathrm{~min}$, rinsed again with $\mathrm{CHCl}_{3}$ and dried with Ar-flow. Successful deposition of OTS monolayer was confirmed with water contact angle measurement $\left(\sim 105^{\circ}\right)$.

Coating of surface: The aryl-azide containing polymers were dissolved in degassed methanol yielding concentrations of 10 and $20 \mathrm{~g} / \mathrm{L}$. Polymer substrate surfaces were washed prior modification for 15-30 min in methanol in ultrasonic bath and dried for another 15 min under high vacuum. The polymer solution was sprayed onto polymer substrates and OTS/silicon 
surfaces, which were mildly heated to $60^{\circ} \mathrm{C}$, using an airbrush. Subsequently the surfaces were irradiated for 20 min using a chromatography lamp VL-4C (254 nm, 8W) which was positioned 2-3 cm above the surfaces. After irradiation the surfaces were washed in methanol for $10 \mathrm{~min}$. The procedure was repeated up to 5 times to improve the result. After the final irradiation step the surfaces were washed more extensively for $60 \mathrm{~min}$ and dried under high vacuum.

$X$-ray photoelectron spectrometry: XPS analyses were carried out on an ESCALAB 250 photoelectron spectrometer from Thermo Electron. Source type was the Al $\mathrm{K}_{\alpha} \mathrm{X}$-ray at $1486.6 \mathrm{eV}$ with an overall instrument resolution of $1.1 \mathrm{eV}$. The spectra were collected from a surface area of $400 \mu \mathrm{m}^{2}$ at an electron takeoff angle of $90^{\circ}$ to the sample surface and calibrated to the binding energy of the $\mathrm{C}-\mathrm{C}$ component of $\mathrm{C}_{1 \mathrm{~s}}$ peak to $284.8 \mathrm{eV}$.

Ellipsometry: Multiple angle of incidence ellipsometry (Optrel, Germany; $\lambda=533 \mathrm{~nm}$ ) was performed on several silicon wafers before and after each step of the surface functionalization. Incident angle was scanned from $70^{\circ}$ to $80^{\circ}$ in $2^{\circ}$ steps. Results have been fitted using a single interfacial layer model. This approximation is justified by the fact that silica, OTS and the grafted polymer layer have approximately the same refractive index, $\mathrm{nL}=1.46$. The thickness reported in Table 1 are calculated by subtracting the thickness of the OTS layer to the total thickness (OTS + grafted polymer layers).

Atomic-force microscopy: AFM studies were carried out on a Nanoman atomic force microscope (Veeco Metrology, Santa Barbara, CA) equipped with a closed loop and run by Nanoscope 5 software (Bruker Instrument). Using an NCL cantilever (Nanosensors, Neuchatel, Switzerland) images were taken in tapping mode under ambient conditions. Images were analyzed via Gwyddion 2.31 software. 
Cell proliferation assay: The coated and non-treated PP and PLA substrates were cleaned with $70 \%$ ethanol and submerged in PBS containing $10 \%$ penicillin/streptomycin over night and finally washed with PBS. The decontaminated surfaces were placed into a 24-well plate. $2 \times 10^{5}$ L929 cells were seeded on each substrate maintained in the wells via a Teflon ring. Tissue culture-treated polystyrene (TCPS) was used as a positive control. After $3 \mathrm{~h}$ incubation at $37^{\circ} \mathrm{C}$ and $5 \% \mathrm{CO}_{2}$ to allow adherence of the cells, the surfaces were washed with PBS and $1 \mathrm{~mL} /$ well culture medium was added. After defined points of time, incubation was stopped, cell culture medium exchanged with medium containing 10\% PrestoBlue ${ }^{\circledR}$ (Invitrogen, A13261), incubated for 30min and the supernatants fluorescence at $590 \mathrm{~nm}$ measured. By adding fresh culture medium again to the surfaces, cell growth was followed over multiple days $(1,3,6$, and 9$)$.

Bacterial strains:The clinical bacterial strains Staphylococcus epidermidis ATCC49461 and Escherichia coli CFT073 were used. Before commencing the antibacterial in vitro tests, the bacterial strains were aerobically grown overnight on Muller Hinton medium at $37^{\circ} \mathrm{C}$ under stirring.

Anti-adherence study: The polymer substrates were submerged in a bacterial solution $\left(\mathrm{OD}_{600}=0.05\right)$. After $1 \mathrm{~h}$ the substrates were rigorously washed 3 times with sterilized water and subsequently immerged in neutral medium for $24 \mathrm{~h}$ at $37^{\circ} \mathrm{C}$ under static conditions. The adhered bacteria were recovered by vortexing and sonication of the substrates in neutral saline. Bacteria were quantified by serial dilution and spread plating on Mueller-Hinton agar. Strongly adhered bacteria were detached by dipping the substrate onto the surface of MuellerHinton agar plates about 15 times. Colony counts were carried out after incubation at $37^{\circ} \mathrm{C}$ over night. Total bacterial adherence was calculated by adding the colony forming unit (CFU) 
counts of all cultivated bacteria. Bacteria were verified by Maldi-Tof analysis (Vitek-MS, BioMérieux).

Biofilm study: The polymer substrates were submerged in wells containing the various bacterial strains diluted in culture medium $\left(\mathrm{OD}_{600}=0.05\right)$. After $72 \mathrm{~h}$ at $37^{\circ} \mathrm{C}$ the substrates were removed from the wells, rinsed vigorously with sterile water and incubated for 10min in $0.1 \%$ crystal violet solution. Excess dye was removed by washing the samples 3 times with sterile water. The bacteria are then precipitated with $250 \mu \mathrm{L}$ DMSO. The obtained solution was spectrophotometrically analyzed to measure the $\mathrm{OD}_{600}$.

\section{Supporting Information}

Supporting Information is available from the Wiley Online Library or from the author.

\section{Acknowledgements}

The authors wish to thank University of Montpellier (UM1 $7^{\text {th }}$ Post-doctoral Fellowship Program) and French Embassy in Germany-Department for Science (French-German Postdoctoral action 2015) for A.S.'s fellowship, Valérie Flaud for the XPS analyses, Michel Ramona for the AFM analyses and Prof. Rainer Jordan for his advice.

Received: ((will be filled in by the editorial staff)) Revised: ((will be filled in by the editorial staff)) Published online: ((will be filled in by the editorial staff))

\section{References}

[1] T. R. Garrett, M. Bhakoo, Z. Zhang, Prog. Nat. Sci. 2008, 18, 1049.

[2] J.M. Schierholz, J. Beuth, J. Hosp. Infect. 2001, 49, 87.

[3] R. O. Darouiche, Clin. Infect. Dis. 2001, 33, 1567.

[4] J. Hasan, R. J. Crawford, E. P. Ivanova, Trends Biotechnol. 2013, 31, 295.

[5] Z.K. Zander, M.L. Becker, ACS Macro Lett. 2018, 7, 16. 
[6] Q. Lu, E. Danner, J. H. Waite, J. N. Israelachvili, H. Zeng, D. S. Hwang, J. R. Soc. Interface 2012, 10, 20120759.

[7] K. Chawla, S. Lee, B. P. Lee, J. L. Dalsin, P. B. Messersmith, N. D. Spencer, J. Biomed. Mater. Res. A 2009, 3, 742.

[8] C. Sardo, B. Nottelet, D. Triolo, G. Giammona, X. Garric, J.-P. Lavigne, G. Cavallaro, J. Coudane, Biomacromolecules 2014, 15, 4351.

[9] S. El Habnouni, J.-P. Lavigne, V. Darcos, B. Porsio, X. Garric, J. Coudane, B. Nottelet, Acta Biomater. 2013, 9, 7709.

[10] G. W. J. Fleet, R. R. Porter, J. R. Knowles, Nature 1969, 224, 511.

[11] A. Klip, C. Gitler, Biochem. Biophys. Res. Communi. 1974, 60, 1155.

[12] K. M. Abu-Salah, J. B. C. Findlay, Biochem. J. 1977, 161, 223.

[13] J. Zhang, Y. Liu,B. Yuan, Z. Wang, M. Schönhoff, X. Zhang, Chem. Eur. J. 2012, 18, 14968.

[14] E. Gérard, E. Bessy, C. Salvagnini, V. Rerat, M. Momtaz, G. Hénard, P. Marmey, T. Verpoort, J. Marchand-Brynaert, Polymer 2011, 52, 1223.

[15] A. J. Gross, S. S. C. Yu, A. J. Downard, Langmuir 2010, 26, 7285.

[16] V. Pourcelle, S. Devouge, M. Garinot, V. Préat, J. Marchand-Brynaert, Biomacromolecules 2007, 8, 3977.

[17] A. Ovsianikov, Z. Li, J. Torgersen, J. Stampfl, R. Liska, Adv. Funct. Mater. 2012, 22, 3429.

[18] A. Zhu, M. Zhang, J. Wu, J. Shen, Biomaterials 2002, 23, 4657.

[19] G. Li, H. Zheng, Y. Wang, H. Wang, Q. Dong, R. Bai, Polymer 2010, 51, 1940.

[20] C. Hadler, K. Wissel, G. Brandes, W. Dempwolf, G. Reuter, T. Lenarz, H. Menzel, Mater. Sci. Eng. C 2017, 75, 286.

[21] M. Barz, R. Luxenhofer, R. Zentel, M. J. Vicent, Polym. Chem. 2011, 2, 1900. 
[22] M. Schneider, C. Fetsch, I. Amin, R. Jordan, R. Luxenhofer, Langmuir 2012, 28, 16099.

[23] S. Palzer, C. Hiebl, K. Sommer, H. Lechner, Chem. Ing. Tech. 2001, 73, 1032.

[24] R. Luxenhofer, Y. Han, A. Schulz, J. Tong, Z. He, A. V. Kabanov, R. Jordan, Macromol. Rapid Commun. 2012, 33, 1613.

[25] W. H. Binder, H. Gruber, Macromol. Chem. Phys. 2000, 201, 949.

[26] C. Fetsch, A. Grossmann, L. Holz, J. F. Nawroth, R. Luxenhofer, Macromolecules 2011, 44, 6746. 
Photoinsertion of rationally designed aryl-azide copolymers is exploited for an efficient and direct surface modification of polymer surfaces. The photografting efficiency is discussed with respect to the macromolecular structures with a pseudo gradient copolymer giving highest efficacy. The versatility of the approach is illustrated with antifouling poly(2oxazoline)-based copolymers to impart antibacterial properties to various clinically relevant polymer substrates.

A. Schulz, A. Stocco, A. Bethry, J.-P. Lavigne, J. Coudane, B. Nottelet*

Direct Photomodification of Polymer Surfaces: Unleashing the Potential of Aryl-Azide Copolymers

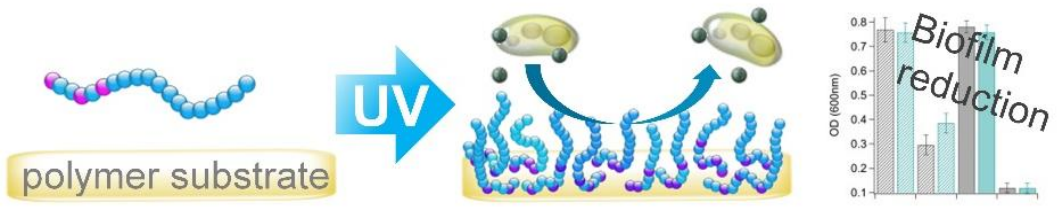




\section{Supporting Information}

\section{Direct Photomodification of Polymer Surfaces: Unleashing the Potential of Aryl-Azide Copolymers}

Anita Schulz, Antonio Stocco, Audrey Bethry, Jean Philippe Lavigne, Jean Coudane, Benjamin Nottelet*

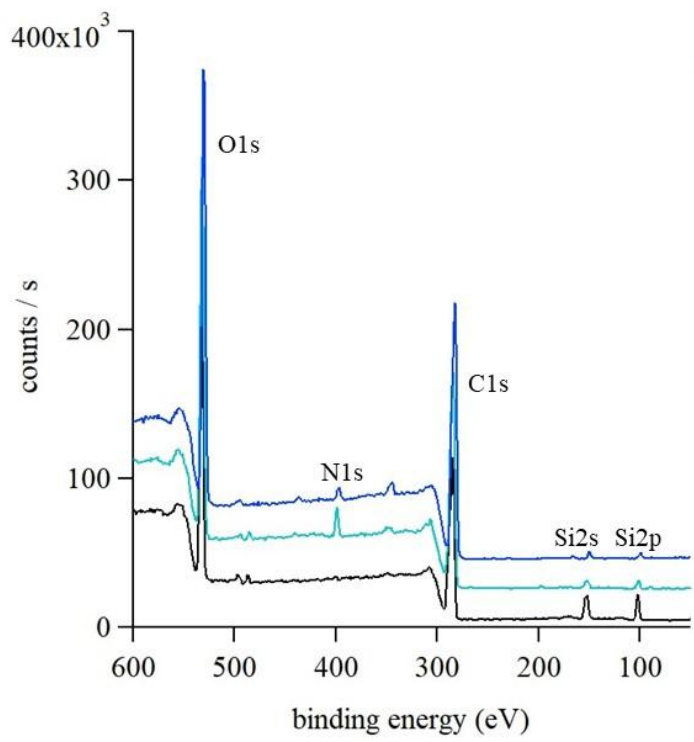

\begin{tabular}{|c|c|c|c|}
\hline \multirow[b]{2}{*}{ PLA } & \multicolumn{3}{|c|}{ At.\% } \\
\hline & $\mathrm{C} 1 \mathrm{~s}$ & O1s & N1s \\
\hline control & 61.5 & 37.3 & 1.2 \\
\hline $\operatorname{PSar}_{100}$ & 65.9 & 33.1 & 1.0 \\
\hline $\mathrm{P}\left[(\mathrm{AzPhOx})_{5}-\mathrm{co}-(\mathrm{MeOx})_{10}\right]-b-(\mathrm{MeOx})_{90}$ & 62.5 & 33.8 & 3.7 \\
\hline
\end{tabular}

Figure S1. XPS full spectrum of PLA substrates and the corresponding atomic percentage.

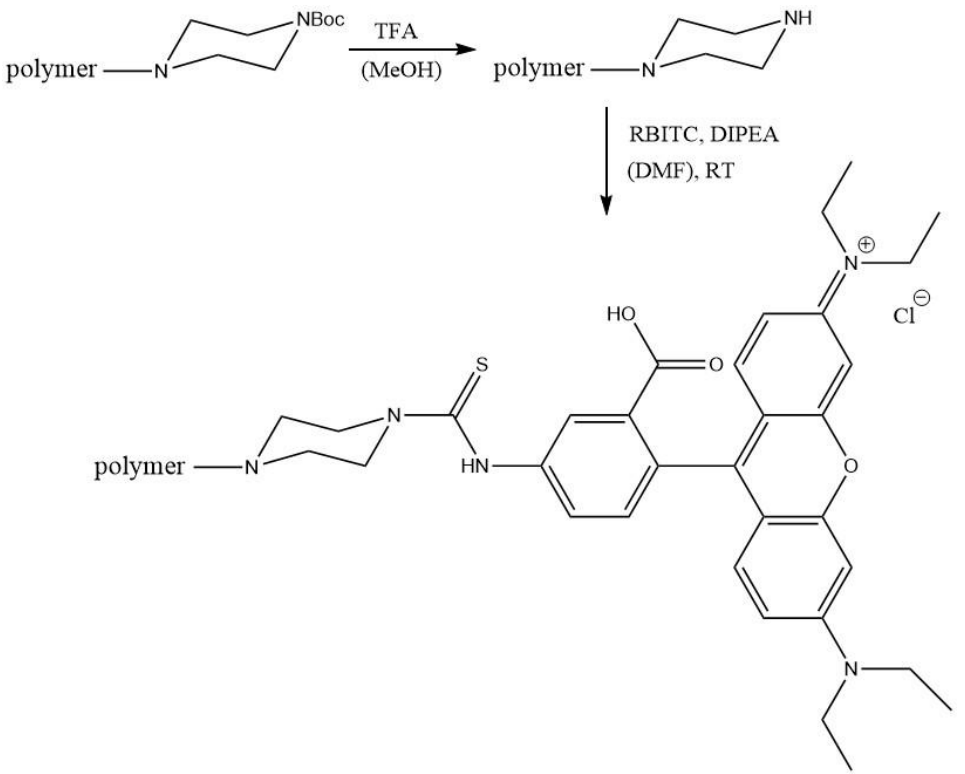

Figure S2. Fluorescent labeling of poly(2-oxazoline)s with Rhodamine B. 

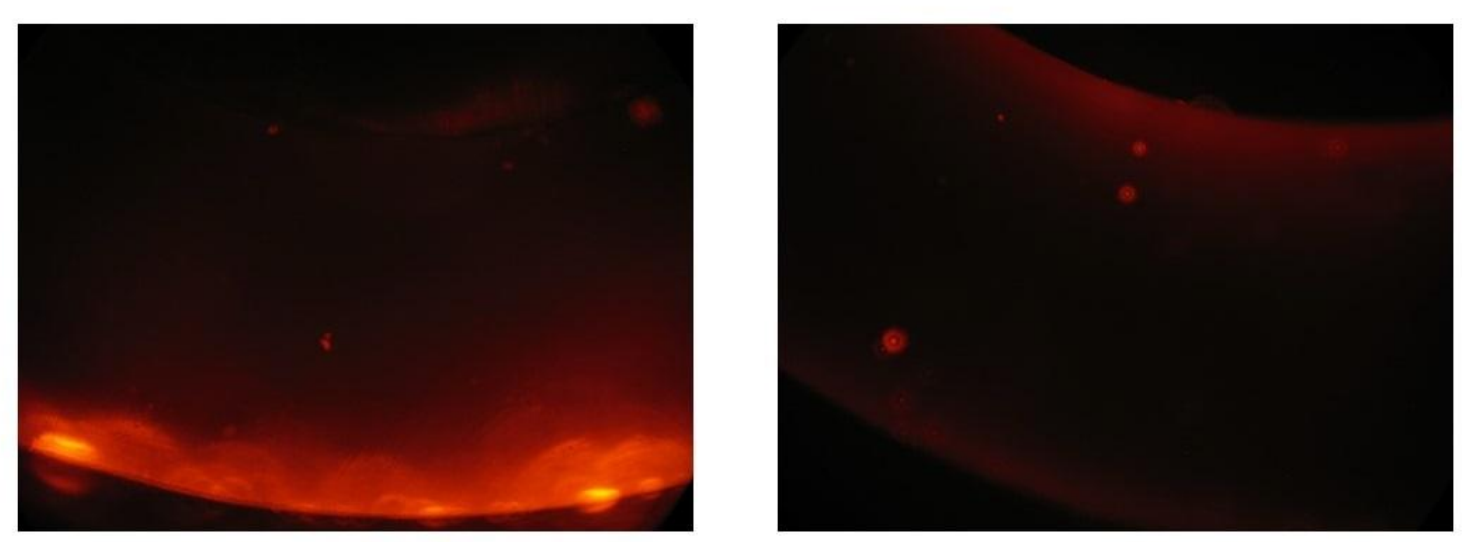

Figure S3. Visualization of the grafting process on a silicone catheter after five coating steps (left) and its thermal stability in $100^{\circ} \mathrm{C}$ hot water (right) by utilizing a fluorescent labeled $\mathrm{P}\left[(\mathrm{AzPhOx})_{5}-c o-(\mathrm{MeOx})_{10}\right]-b-(\mathrm{MeOx})_{90}$ copolymer.

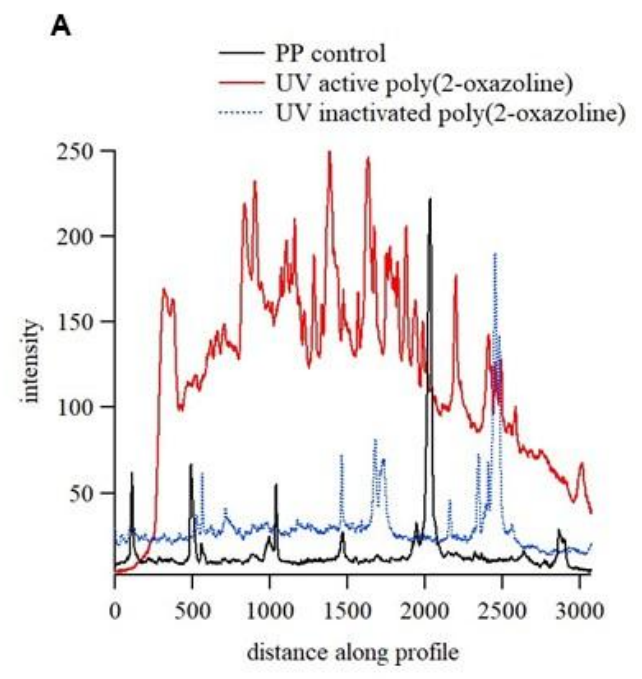

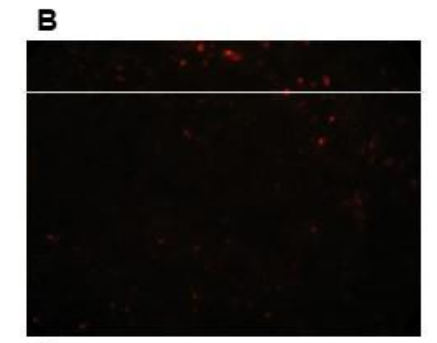

D
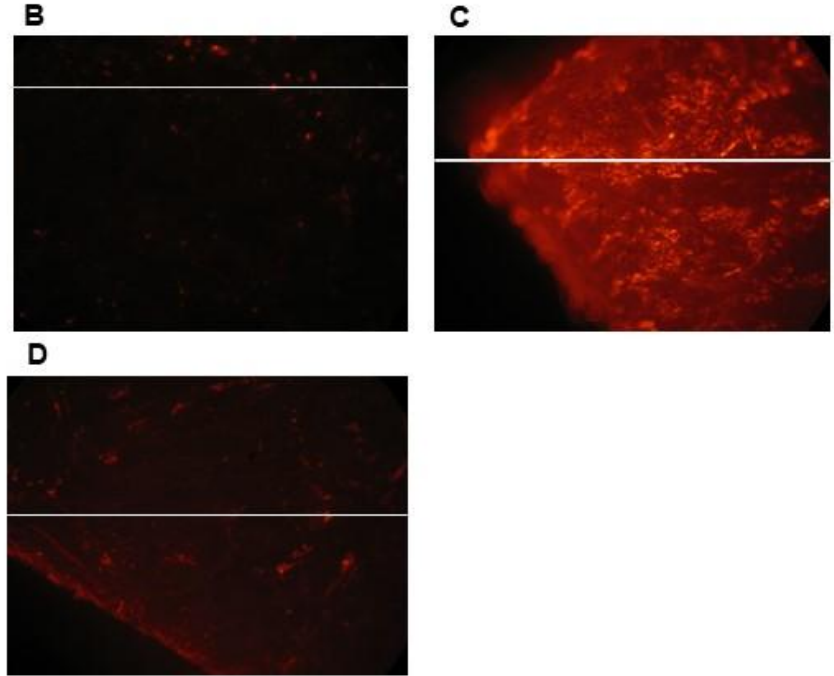

Figure S4. Line profiles of the individual red component along the specified path of all surface images shown (A). Fluorescence microscopy images of untreated PP surface (B), PP surface $5 \mathrm{x}$ irradiated for 20 min with $\mathrm{UV}$ active $\mathrm{P}\left[(\mathrm{AzPhOx})_{5}-c o-(\mathrm{MeOx})_{10}\right]-b-(\mathrm{MeOx})_{90}(\mathrm{C})$ and with UV inactivated $\mathrm{P}\left[(\mathrm{AzPhOx})_{5}-c o-(\mathrm{MeOx})_{10}\right]-b-(\mathrm{MeOx})_{90}(\mathrm{D})$. 

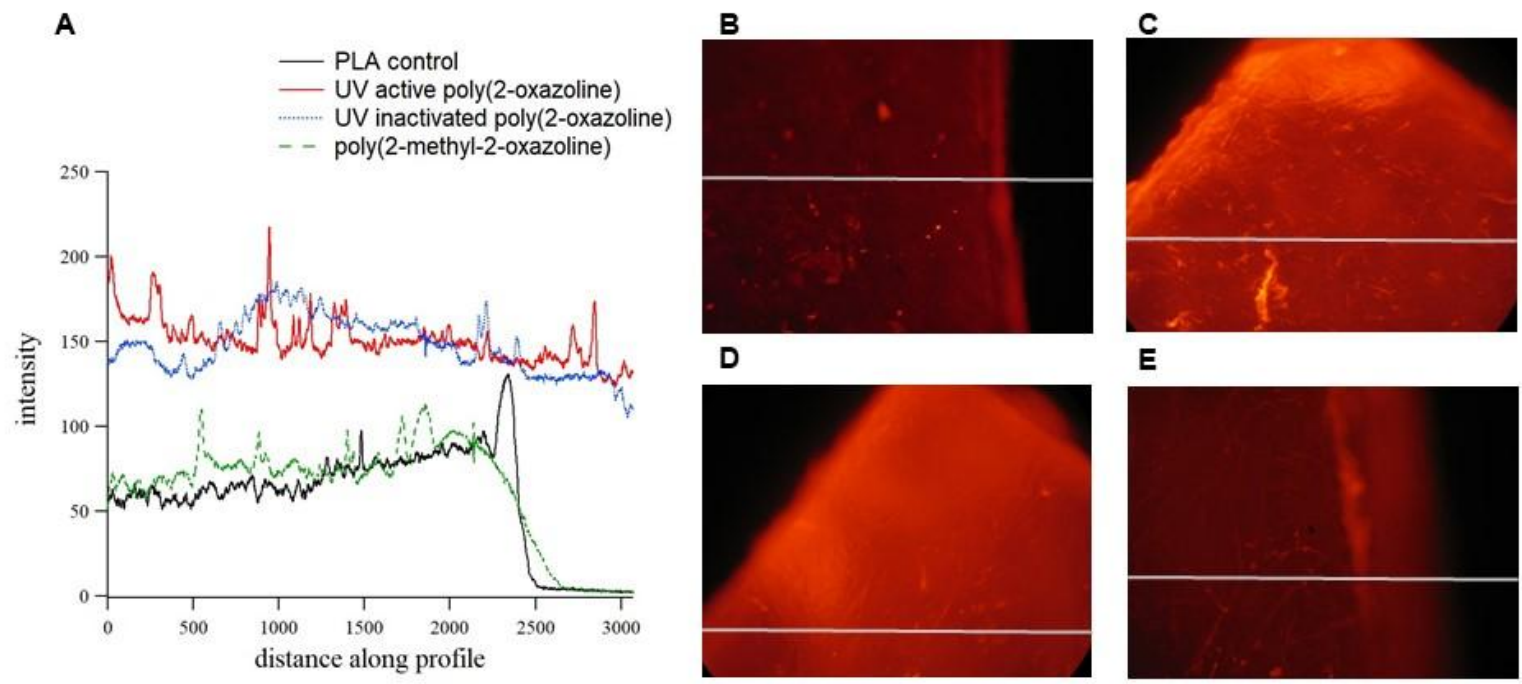

Figure S5. Line profiles of the individual red component along the specified path of all surface images shown (A). Fluorescence microscopy images of untreated PLA surface (B), PLA surface $5 \mathrm{x}$ irradiated for 20 min with UV active $\mathrm{P}\left[(\mathrm{AzPhOx})_{5}-c o-(\mathrm{MeOx})_{10}\right]-b-(\mathrm{MeOx})_{90}$ (C), with UV inactivated $\mathrm{P}\left[(\mathrm{AzPhOx})_{5}-\mathrm{Co}-(\mathrm{MeOx})_{10}\right]-b-(\mathrm{MeOx})_{90}(\mathrm{D})$ and with $\mathrm{PMeOx}_{60}(\mathrm{E})$.

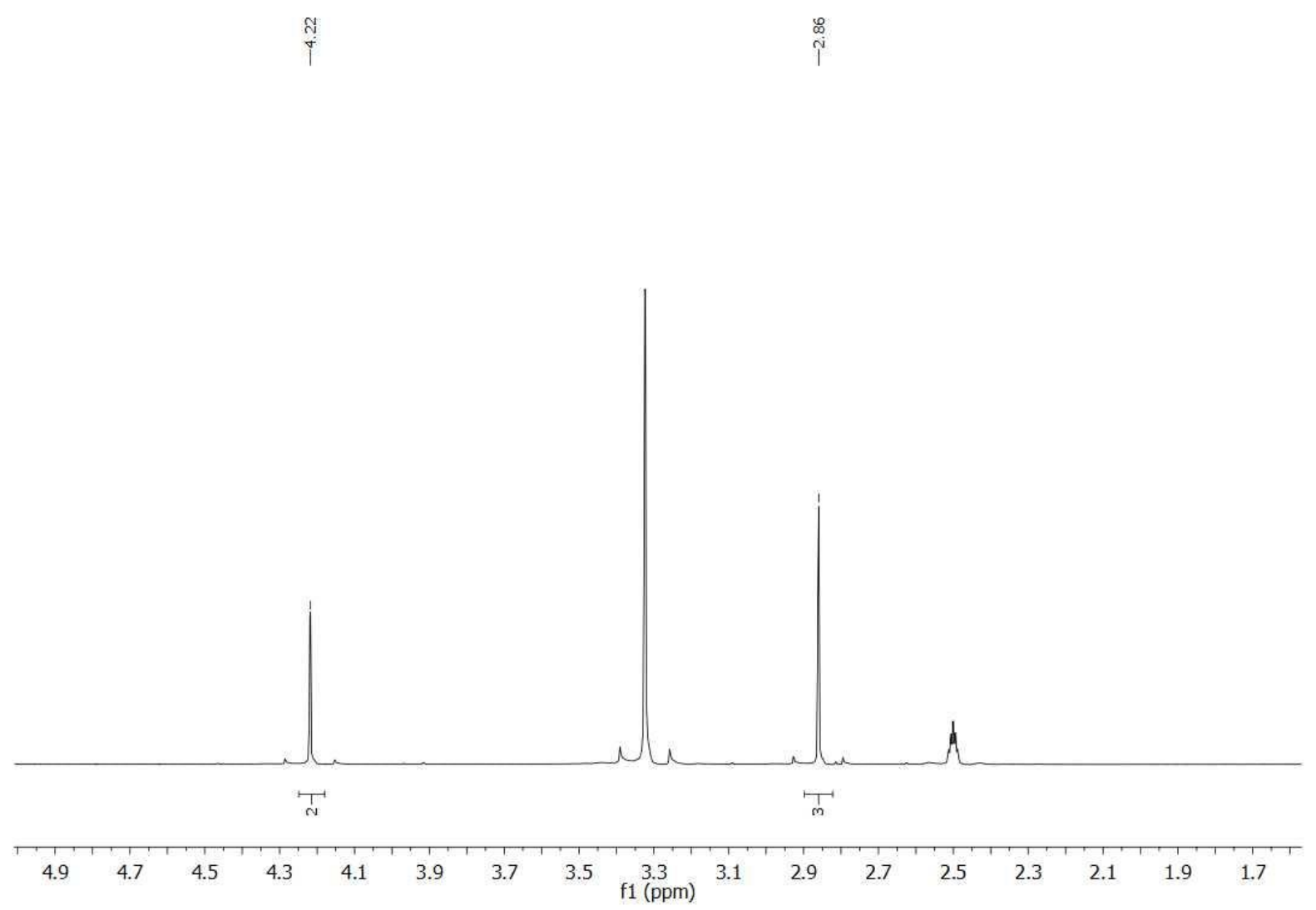

Figure S6. ${ }^{1} \mathrm{H}-\mathrm{NMR}$ of sarcosine- $N$-carboxyanhydride in DMSO. 


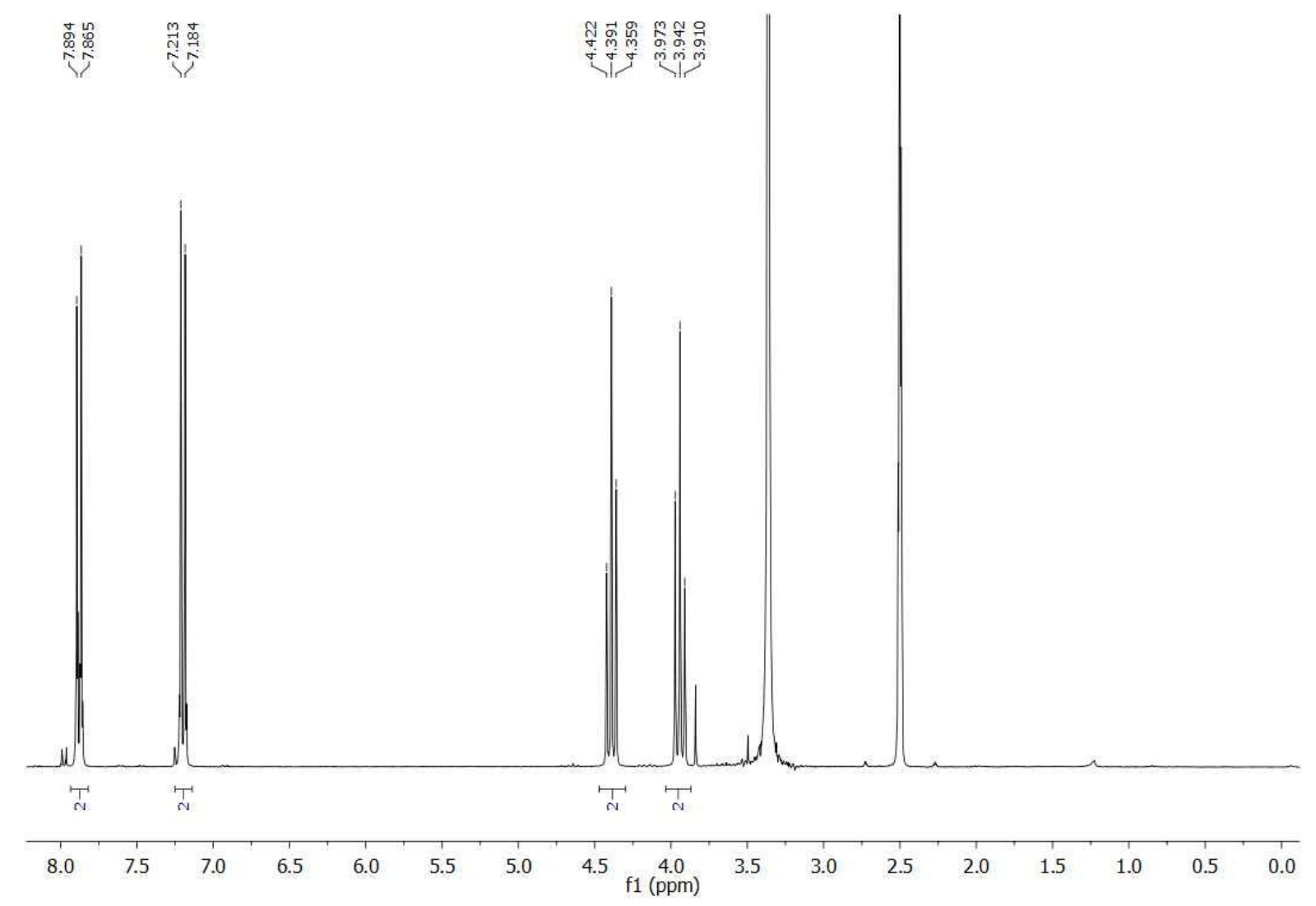

Figure S7. ${ }^{\text {H}} \mathrm{H}-\mathrm{NMR}$ of 2-(4-azidophenyl)-oxazoline in DMSO.

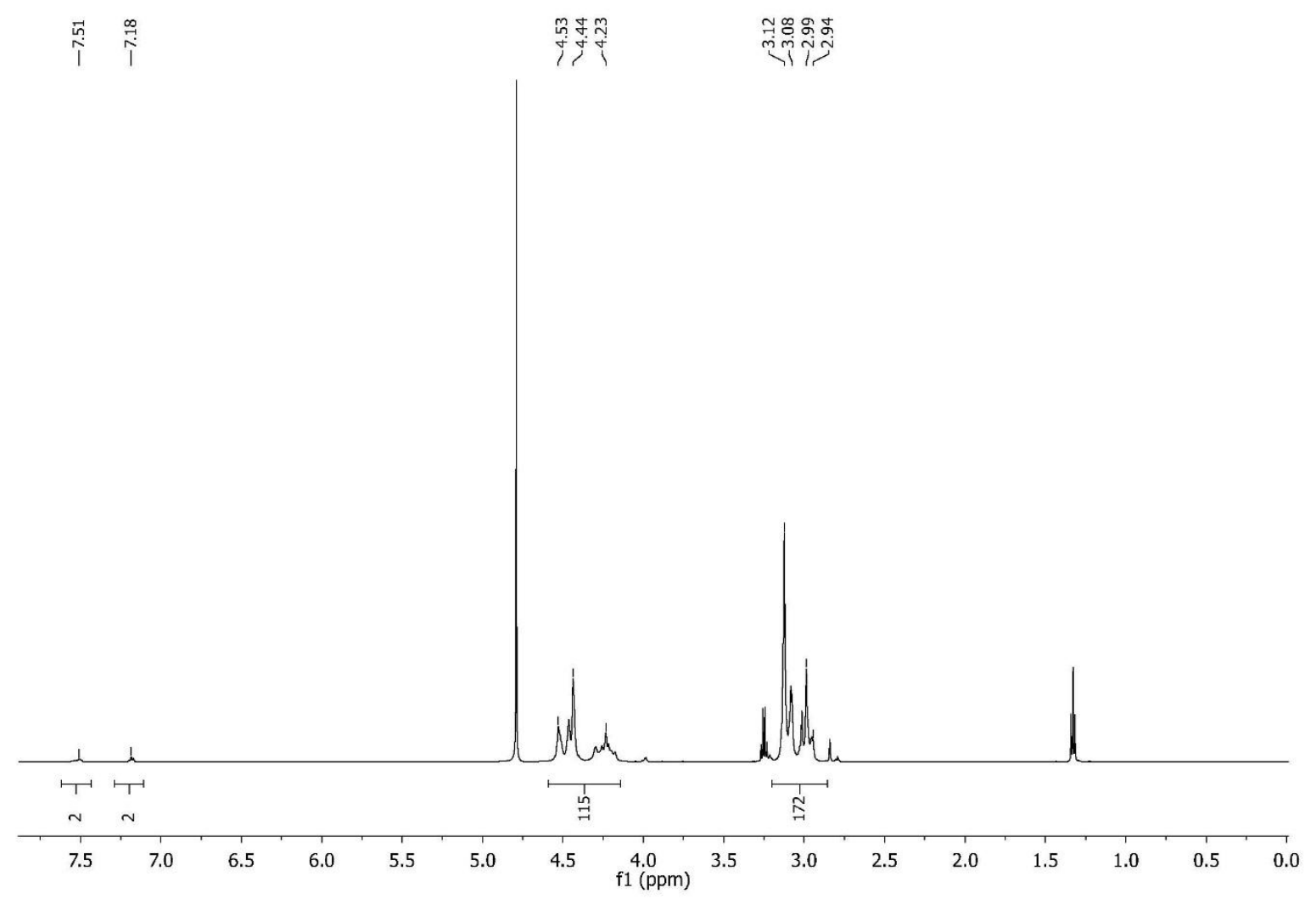

Figure S8. ${ }^{1} \mathrm{H}-\mathrm{NMR}$ of $\mathrm{AzPh}-\mathrm{PS} \operatorname{sar} 10$ in $\mathrm{D}_{2} \mathrm{O}$. 


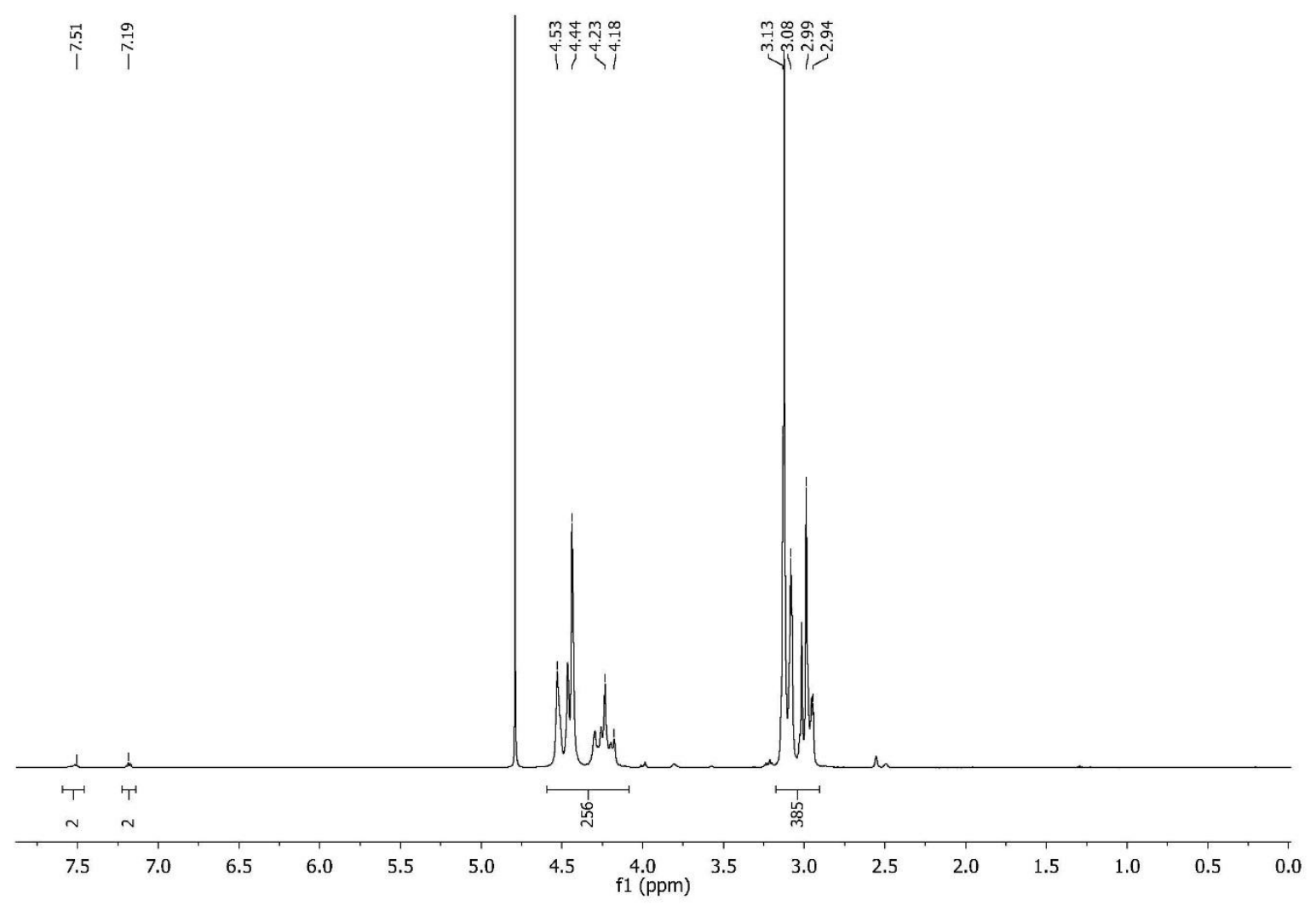

Figure S9. ${ }^{1} \mathrm{H}-\mathrm{NMR}$ of $\mathrm{AzPh}-\mathrm{PSar}_{100}$ in $\mathrm{D}_{2} \mathrm{O}$.

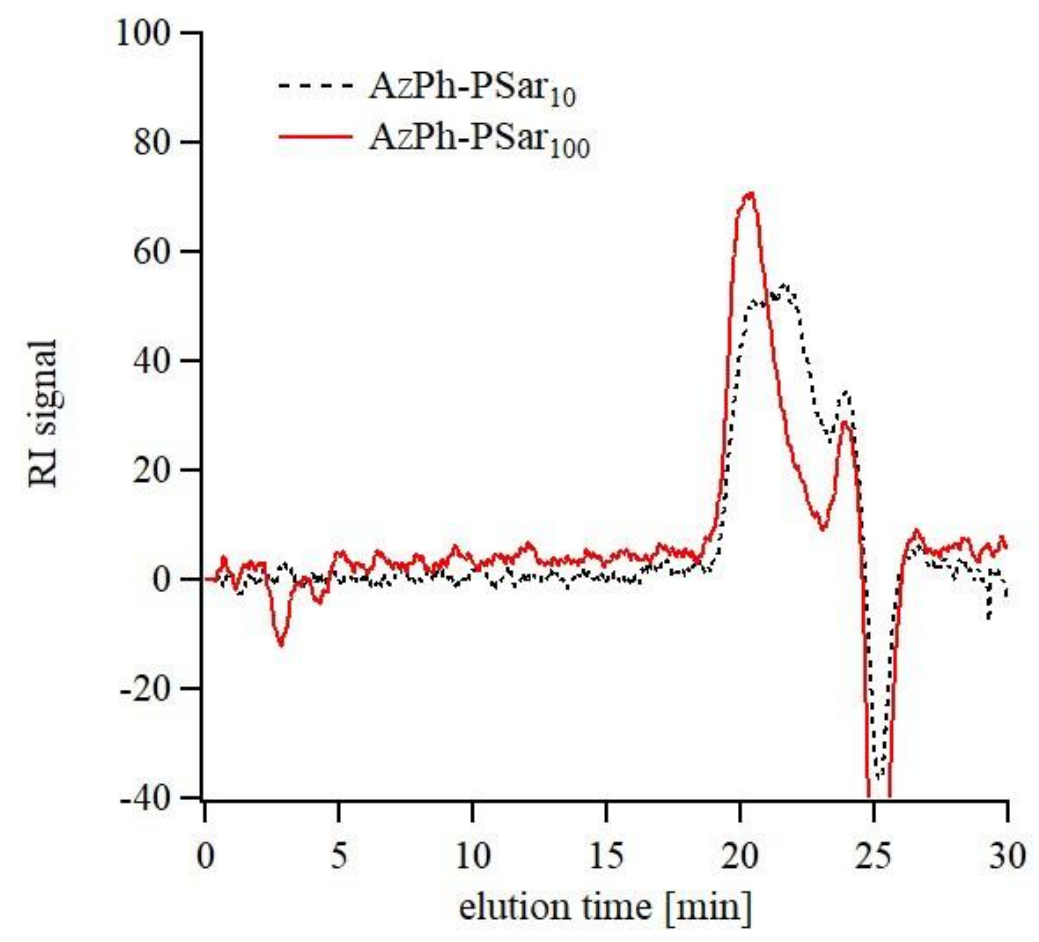

Figure S10. GPC elugram of AzPh-PSar in DMF. 


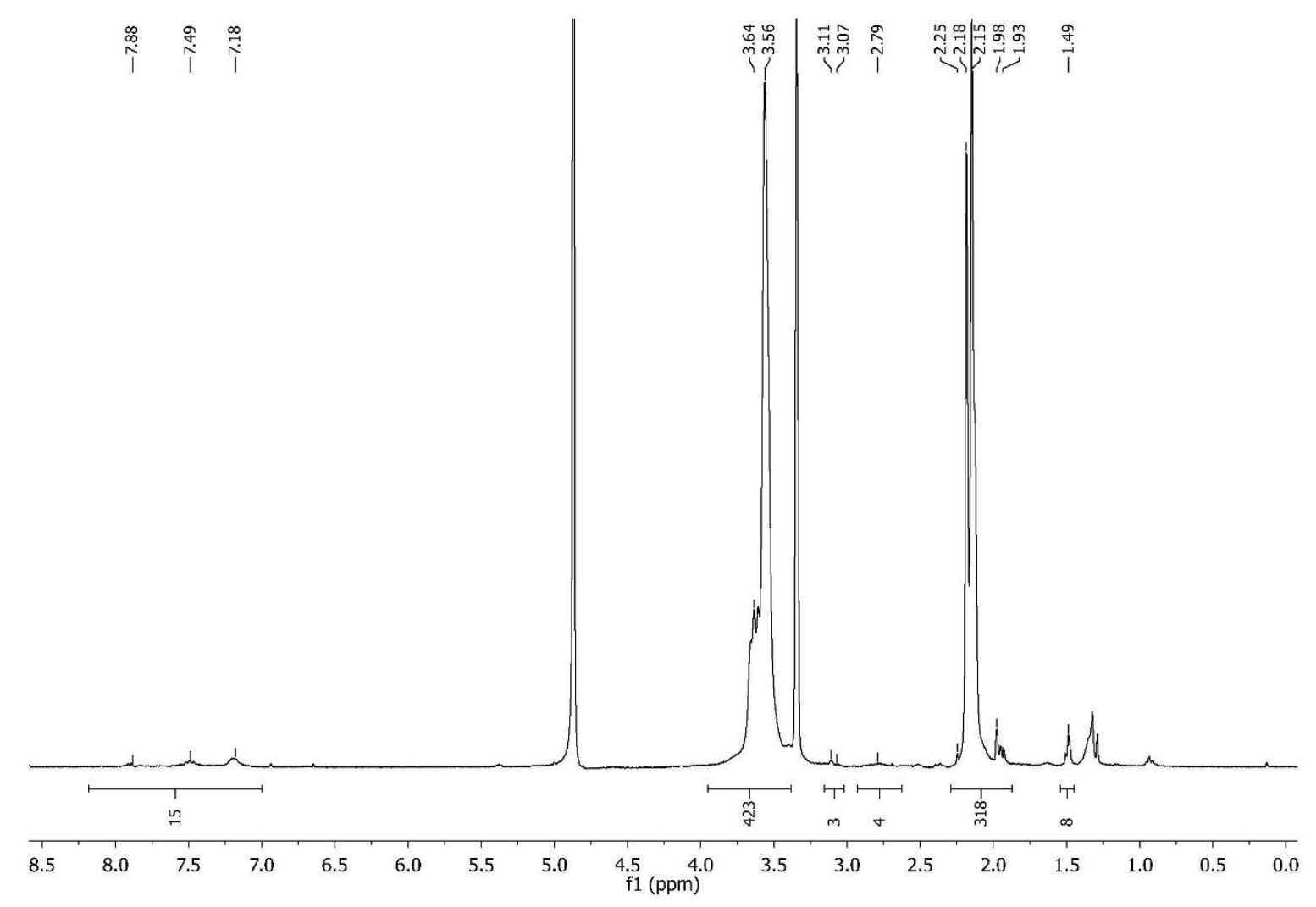

Figure S11. ${ }^{1} \mathrm{H}-\mathrm{NMR}$ of $\mathrm{P}(\mathrm{AzPhOx})_{5}-b-(\mathrm{MeOx})_{100}$ in $\mathrm{MeOD}$.

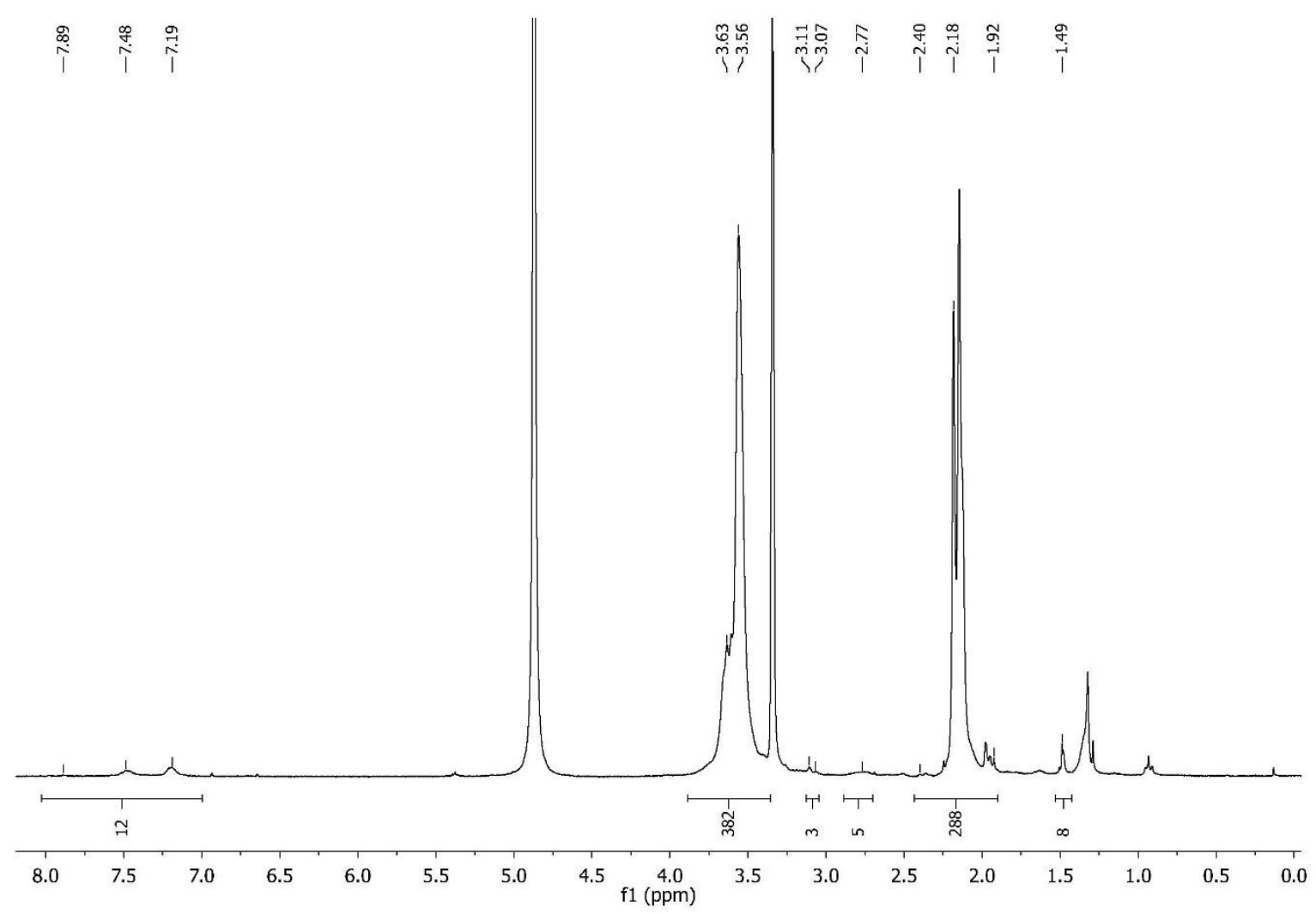

Figure S12. ${ }^{1} \mathrm{H}-\mathrm{NMR}$ of $\mathrm{P}\left[(\mathrm{AzPhOx})_{5}-c o-(\mathrm{MeOx})_{10}\right]-b-(\mathrm{MeOx})_{90}$ in $\mathrm{MeOD}$. 


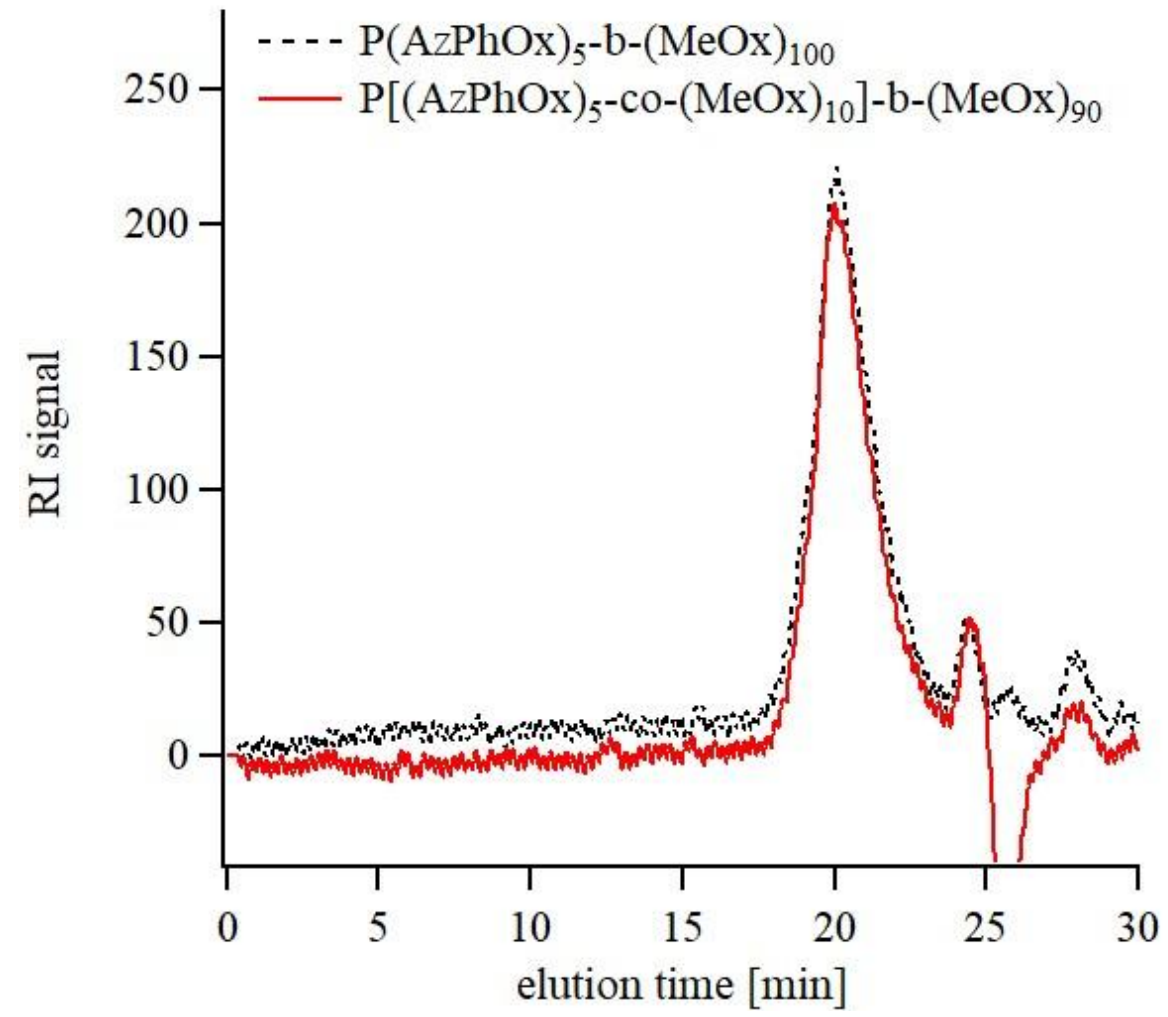

Figure S13. GPC elugram of poly(2-oxzaline) copolymers in DMF.

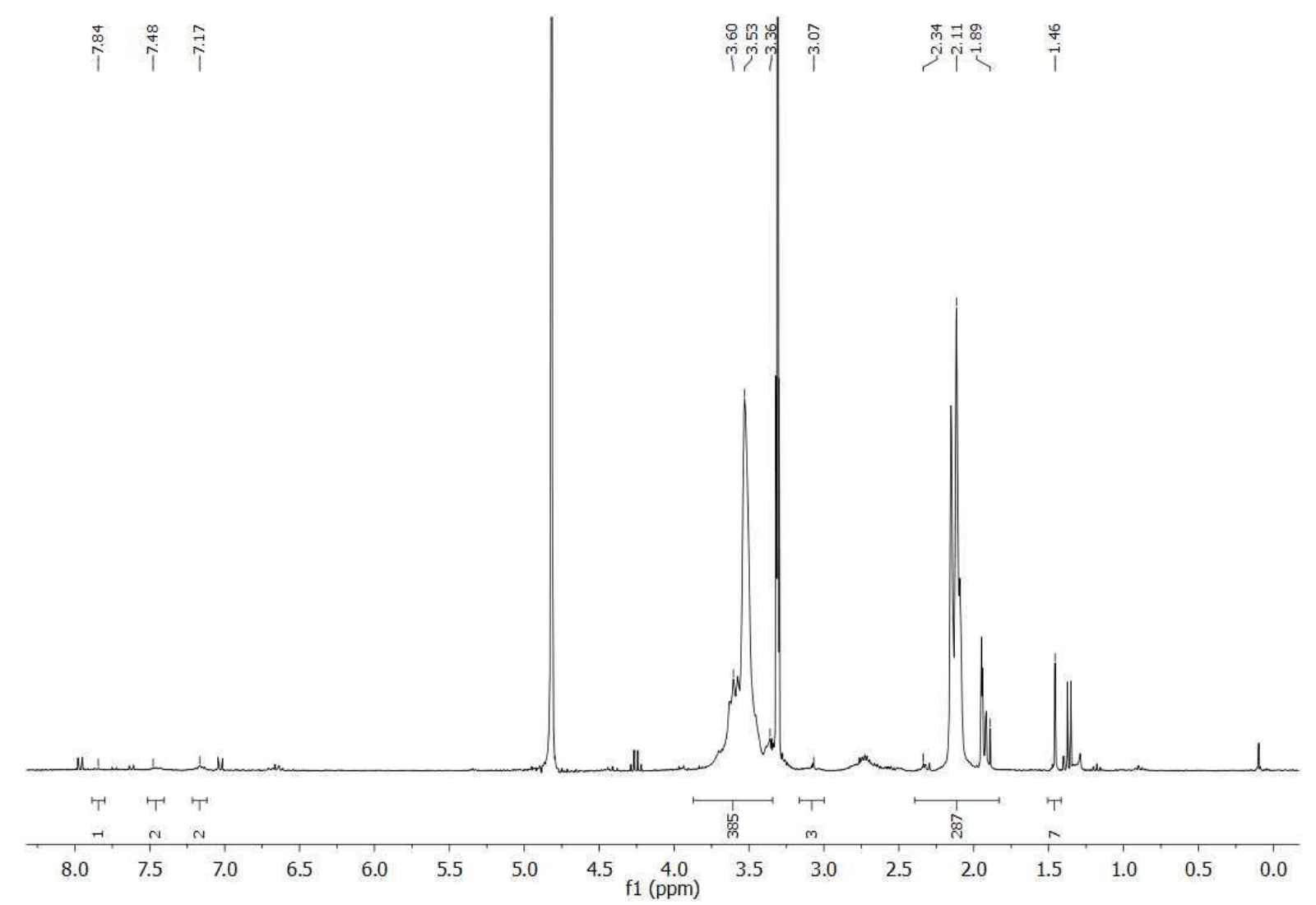

Figure S14. ${ }^{1} \mathrm{H}-\mathrm{NMR}$ of $\mathrm{P}(\mathrm{AzPhOx})_{1}$-co-(MeOx $)_{100}$ in $\mathrm{MeOD}$. 